NASA Technical Memorandum 85637

NASA-TM-85637 19830020899

\title{
HISTORICAL DEVELOPMENT OF WORLDWIDE SUPERSONIC AIRCRAFT
}

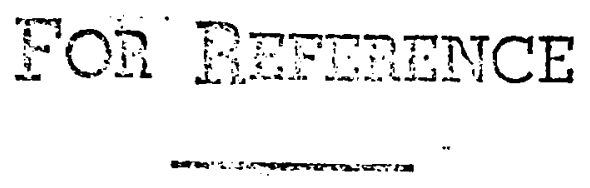

NOT TO EE TAEET TEOM

\section{Leroy Spearman}

MAY 1983

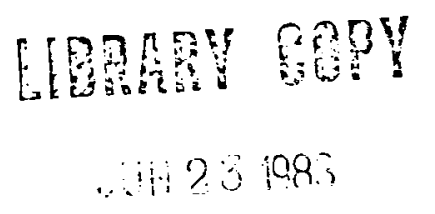

N/S

Larigley RESEARSCH CENTER

LIBEARY, NASA

HEMPETON, VIRGIMIA.

National Aeronautics and

Space Administration

Langley Research Center

Hampton, Virginia 23665 
31176013090494 


\section{SUMMARY}

The most dramatic developments in man's quest for increased speed have occurred with the airplane. This paper traces some of the major milestones in the progression of airplane speeds from subsonic to supersonic. While some historical background is included on work done prior to the twentieth century, the major emphasis is on the twentieth century developments after the man-carrying airplane became a practical reality. The techniques of increasing airplane speed revolve around means of increasing the propulsive force and means of reducing the airframe resistance (drag). With the changes in speed, the attendant changes in flow patterns due to the compressibilty of air introduce some aerodynamic problems. In addition, geometric changes introduced to combat the effects of compressibility also promote aerodynamic problems. Some of the solutions to these problems are illustrated, and many innovative design features that have evolved are discussed.

\section{INTRODUCTION}

For thousands of years, mankind has been upgrading the methods and means of transportation by land, water, and, finally, air. There has always been a human urge both to move more and to move faster. The progression has included walking; the use of animals; the discovery of the wheel, which, in turn, lead to handcarts, and when combined with animal power, to chariots, wagons, and carriages. Other forms of power lead to the development of cycles; the horseless carriage (automobile); trucks and busses. Wheels were also used in the development of tracked trolleys and trains. Water travel progressed from floating on a log to dugouts; rafts; galleys propelled by oars and sails; large sailing vessels; steamships; and nuclear ships. Flight through the air found a place in Greek mythology with Daedalus and Icarus flying with wings of feathers and wax. Leonardo da Vinci envisioned man-flight in the fifteenth century. The early use of reaction propulsion in rockets of the tenth century began to lead to ideas that would eventually be used in the development of man-carrying supersonic airplanes. In the mid $1600^{\prime}$ 's, Titus Livius Borattini invented heavierthan-air flying ships that separated the apparatus into lift supplied by wings and thrust supplied by jet engines. In the eighteenth century, Emanuel Swedenborg laid out the design for a fixed-wing airplane. Un November 21, 1783, P. de Rozier and M. D'Arlandes first flew, going aloft in a Montgolfier brothers hot-air balloon. In the late 1800's, Otto Lilenthal made hundreds of glider flights, and was a great inspiration to the Wright brothers. During the 1880's, Sergei Sergeevich Nezhdanovsky discussed the design of jet airplanes with wings.

Space does not permit mentioning the accomplishments of many others. While several people were bordering on the achievement of successful manned, powered, flight, the Wright brothers are credited with the first officially acknowledged controlled and sustained flight of an airplane at Kill Devil Hills, North Carolina, on December 17, 1903. From that point on, the advancements in man's quest for speed have been remarkable. 
SYMBOLS

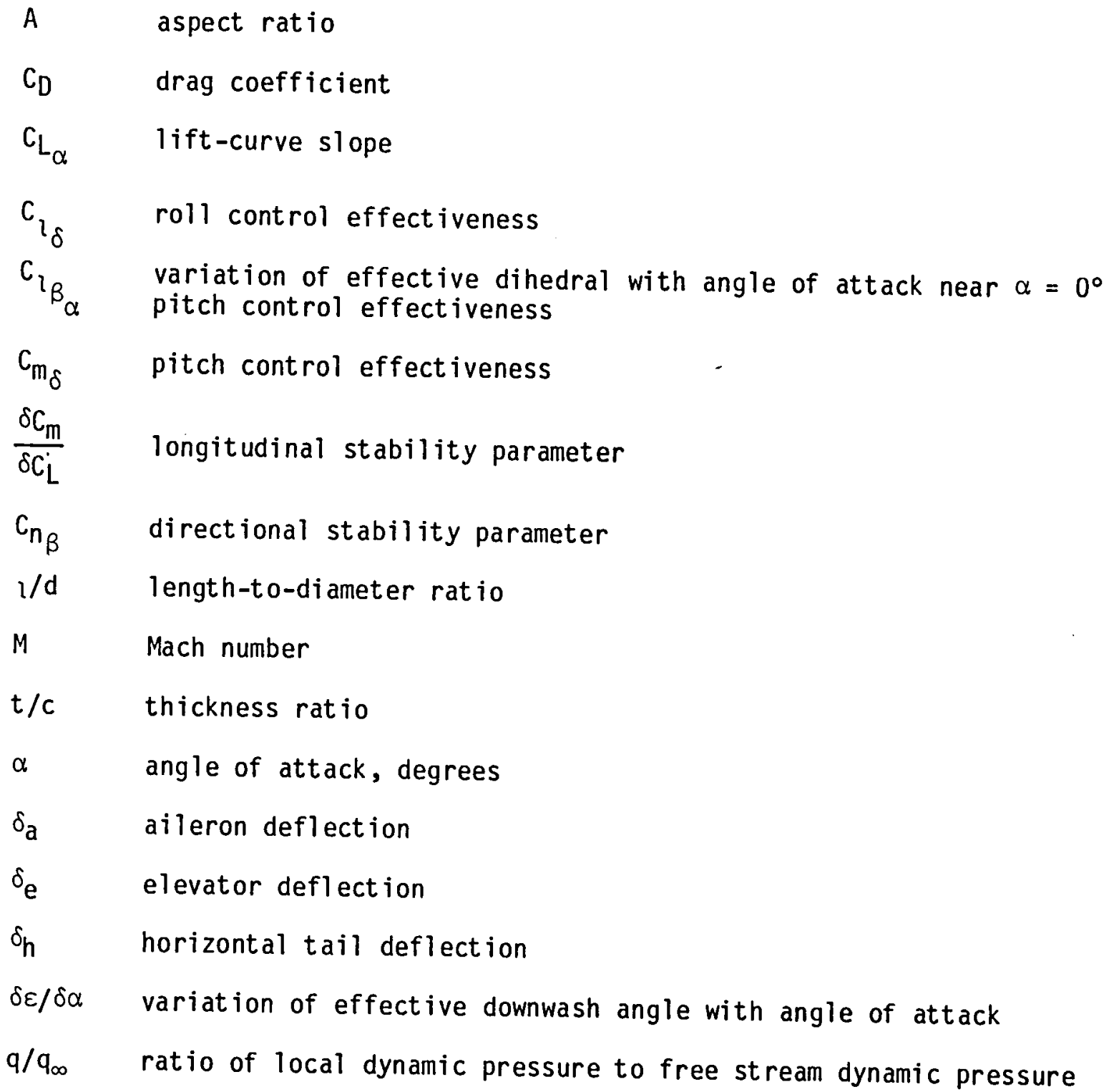

\section{DISCUSSION}

Between World War I and World War II, airplane speeds steadily increased. During World War II, speeds became limited for propeller-driven aircraft and the time had come for the impact of reaction-propelled flight to be realized. Many developments for reaction-propelled airplanes began to take place in many countries. Developments in Germany are of particular interest. Erich Warsitz made a series of successful flights with the first rocket-powered Heinkel 112 in 1937. This led to the development of a small, rocket-powered fighter, the Heinkel 176--but with the outbreak of the war, the project was shelved after several successful flights. It was only near the end of the war that rocket-powered airplanes, such as Lippisch's Me 163, made a dramatic, though limited, comeback. Some German jet-propelled fighters, such as the Me 262 twin-engined airplane, also saw limited service near the end of the war. German scientists had begun making strides into supersonic aerodynamics with missiles such as the $A-4(V-2)$, one of which, on a ballistic flight, achieved a speed of 
$M=4.7$ and altitude of 275,000 feet, and a range of $116 \mathrm{miles,} \mathrm{on} \mathrm{0ctober} \mathrm{3,} 1942$ (41 years ago). The maneuverable Wasserfall winged surface-to-air missile, designed for $M=3$, made forty-four successful flights in the 1944 time period. A winged version of the $A-4$, the $A-9$, successfully flew to $M=4$ during the winter of 1944-45. Further plans for the A-9, that were curtailed by the ending of the war, included a manned-version with a pressurized cockpit and tricycle landing gear, that was to fly at $M=2$ for 400 miles. A rocket-boosted manned A-9 was also envisioned that would have transatlantic range. Much of the German (and axis-partner, Italian) work in high-speed aerodynamics fell into the hands of the Allied nations at the end of World War II and was useful in stimulating research in other countries.

\section{Early Studies of Compressibility}

Many theoretical and experimental studies were made early in the Twentieth Century that dealt with the problems of supersonic flows. A few will be mentioned here to provide some historical background for the real-world flight problems that were to occur later. In 1908, L. Prandtl and T. Meyer made calculations for possible deflections of supersonic streams around corners. J. Ackeret was studying the forces on airfoils moving faster than sound in 1925. H. Glauert was studying the effect of compressibility on the lift of airfoils in 1927. Supersonic wind tunnel verification of Ackeret's theory of airfoils was made by G. I. Taylor in 1932. T. von Karman and N. B. Norton were studying the resistance of slender bodies at supersonic velocities in 1932. Other work includes Crocco's computation of the flow pattern behind a shock wave (1937); Tsien on the flow over inclined bodies at supersonic speeds (1938); Schlichting's airfoil theory at supersonic speeds (1939); Ferri's high-speed tests with airfoils at Guidonia (1939); J. Stack's work on compressibility beginning in the 1930's and extending into the 1940's; Busemann's calculations of conical pressure

fields over bodies in supersonic flow (1942-43); and the work of R. T. Jones on wings and bodies in supersonic flows beginning about 1945.

\section{The Coming of the Jets}

The first American jet propelled airplane, the Bell P-59 Airacomet (fig. 1) powered by two General Electric engines, was under secret development in the early 1940's and was first flown on October 1, 1942. Bell produced sixty-six Airacomets and they were provided to the AAF for training. Early in 1945, an Associated Press story with a Moscow dateline reported that the Airacomet was the first Allied jet airplane to be put into action, having been used against German robot bombs. Other jet airplanes that pushed to the border of sonic flight soon appeared. These airplanes were limited by the onset of compressibility effects and experienced large drag increases and marked changes in stability and control. Some of these effects had been experienced by high-speed propeller-driven airplanes such as the North American P-51 Mustang and the Lockheed P-38 Lightning. One problem in particular was the phenomena of "tucking under." This was characterized by a severe nose-down tendency at high speeds with an attendant decrease in control power to effect a normal recovery. "Wing dropping" was another phenomena that began to appear. This was characterized by an unwanted roll tendency apparently induced by span loading changes caused by asymmetry and further aggravated by a decrease in aileron effectiveness necessary for corrective action. 
New Test Techniques

Conventional wind tunnels of the mid 1940's were not able to test near $M=1$ because of the same compressibility and shock wave effects that airplanes were beginning to experience except that, in the case of the wind tunnel, the presence of the tunnel walls resulted in reflected shocks that disrupted the tunnel flow. Alternate methods used in the early 1940's for obtaining transonic data included free-fall drop models; the wing-flow and transonic-bump techniques; and free-flight, rocket-propelled models. These techniques were soon to be followed by the X-series of flight research airplanes. In addition, the slotted-throat transonic tunnel was being developed under the direction of John Stack and in December 1949, the converted 8-foot transonic tunnel was operated at NACA-Langley, followed a year later by the 16-foot transonic tunnel.

\section{Supersonic Phenomena}

The sound barrier.- Through the use of the newly developed test techniques, along with the existing subsonic and supersonic wind tunnels, a storehouse of data was soon being produced to aid in the development of a rapidly emerging generation of new supersonic airplanes. Probably the most troublesome problem to initially plague supersonic flight was that of compressibility. This effect is illustrated in figure 2. A disturbance in free air is propagated at the speed of sound. At low speeds these disturbances propagate in all directions including forward. As the speed of the disturbance approaches the speed of sound $(M=1)$, there can be no forward propagation and the air begins to compress at the forward edge of the disturbance giving rise to shock formations and increased drag. This inherent barrier became known as the "sonic barrier" or "sound barrier" and, at times, appeared to be insurmountable. With further increases in the speed of the disturbance $(M>1)$, all propagations of the disturbance are confined to circular areas outward and rearward that can be bound into Mach cones and there can be no disturbance forward of the Mach cones.

Transonic drag and lift.- Transonic drag characteristics obtained from early free-flight rocket-propelled models are shown in figure 3 . The body-tail results indicate a substantial transonic drag increase for the $l / d=6$ body--in this case, an increase by a factor of almost 6--and show the desirability of using more slender bodies, such as shown by the $l / d=12.5$ body, to obtain a marked reduction in the transonic drag rise (a factor less than 2). The effects of wing sweep for a bodywing-tail model are also shown in figure 3. As indicated by earlier calculations, increasing the wing sweep angle was shown to be an effective means for reducing the drag rise.

Transonic lift and drag characteristics of wings as determined by the transonicbump technique are shown in figure 4 . The thickness ratio results indicated that the thicker wing sections $(t / c=0.12)$, typical of subsonic airplanes, promoted severe compressibility and shock flow effects that not only cause large increases in transonic drag, but also cause irregular changes in $C_{L_{\alpha}}$ indicative of shock-induced flow separation. Reducing the value of $t / c$ to 0.06 and 0.04 progressively reduced the drag rise and increased $C_{L_{\alpha}}$. The effect of wing sweep is again shown to dramatically reduce the transonic drag rise. The variation of $C_{L_{\alpha}}$ with $M$ shows the effect of shock flow for the unswept wing. With increasing wing sweep, this effect disappears and $C_{L_{\alpha}}$ progressively decreases. The design trends that began to emerge for supersonic airplanes thus began to show the use of swept wings; thinner wing 
sections; and long, slender bodies. In addition, there was a tendency for the center of gravity to move rearward because of the location of jet engines near the rear. These design trends for achieving supersonic flight were, in some cases, to become contributors to new types of stability problems.

Area distribution.- Since it was clear that compressibility and shock-induced phenomena were a function of the amount of disturbance imparted to the surrounding air, the thought of lessening the disturbance became important. Through the work of Dr. Richard T. Whitcomb and others, the concept of the transonic area rule was developed in the early 1950's. Simply stated, the rule says that the cross-sectional area of an airplane should vary as gently as possible from the front to the back (fig. 5). The ideal equivalent body should be as nearly parabolic and as slender as possible. The addition of wings to a body, for example, which would normally add extra crosssection area, could be compensated by locally removing some area from the body. This approach soon lead to the terms "wasp-waisted" or "coke-bottle" shape. The concept did prove to be correct and a major aid to overcoming the drag rise was available. Later developments of the "supersonic area rule" were devised for reducing the supersonic wave drag. With this technique, it is necessary to determine the average equivalent body determined by viewing the area progression along Mach lines for a given supersonic Mach number. The application of the smooth area distribution techniques has been a valuable tool in the design of supersonic airplanes. It is not necessary, as once thought, that the airplane present a "coke-bottle" body shape. It is only necessary that the area distribution be smooth and this effect can be achieved by various means including careful location of components, shaping of planforms, selection of airfoils, and so on.

Downwash characteristics.- Another aerodynamic change observed from early transonic-bump tests was the downwash variation with $M$ for aft tail airplanes. The observed characteristic (fig. 6) was the gradual reduction in the effective downwash at the tail with increasing $M$ and, often, the appearance of an upwash at supersonic speeds. The loss in downwash occurs primarily because the major portion of the downwash is generated by the wing-tip vortex which, at supersonic speeds, is confined to the tip Mach cones and progressively begins to effect less of the tail. The appearance of upwash may occur from cross flow around the body as angle of attack is increased. As a result of this particular characteristic, the horizontal tail, which is sized to account for the downwash at subsonic speeds, becomes increasingly effective and contributes to an overall trend toward increased longitudinal stability in the transonic range. Some design trends that have been partly influenced by the downwash characteristics are the tailless designs and canard designs. The vertical location of the horizontal tail with respect to the wing also became a design trade factor from a stability as well as a structural standpoint.

Longitudinal stability.- The variation of the longitudinal stability parameter,

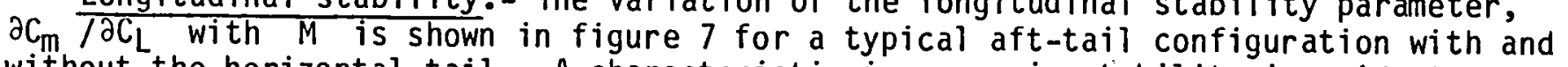
without the horizontal tail. A characteristic increase in stability is evident through the transonic range both with and without a horizontal tail. One of the main contributing factors to this increase is a rearward center of pressure shift for airfoils as shock flow eliminates the forward, upper surface, negative pressure peak, and the lift increases over the rearward portion of the airfoil. The aft shift in center of pressure is generally large enough so that a conventional airplane configuration becomes statically stable even with the horizontal tail off. Other contributing factors to the increase in stability is the effect of carry-over lift from the wing to the body. Above $M=1$, the wing-lifting pressures are confined to the Mach cones and thus increase the lift over the body aft of the wing. While the decrease in downwash at the tail is also stabilizing, this effect is offset by a decrease in tail 
lift curve slope at supersonic speeds. The primary problem associated with the increased longitudinal stability is the increased control power required to provide for trimming which, in turn, reduces the ability to maneuver. A lack of control power contributed to the danger of the "tucking-under" tendency of early high speed aircraft. The presence of this problem lead to the use of all-moving horizontal tails for pitch control to replace the long standing, conventional elevator. When large deflections of an aft tail became necessary for trimming excessive longitudinal stability, the attendant consequences were high trim drag, large-lift losses

(decreased lift-drag ratio at trim), and control-limited maneuver and level-flight altitude capability. The use of delta wing tailless configurations, while alleviating some of the supersonic lift, drag, and stability problems, also introduced some problems. For example, the use of wing trailing-edge elevons for pitch control subtracted directly from the wing lift while adding to the drag, and when combined for pitch-roll control could lead to control deflection limitations. In addition, the use of trailing-edge flaps for high-lift devices was prohibited. It is interesting to note that some early Soviet supersonic design not only employed swept wings with aft tails but, also, exploited the benefits of the thinner, low-aspect-ratio, delta wing in combination with an aft tail for pitch control.

Additional supersonic longitudinal stability problems at high angles of attack were related to the geometric characteristics of some airplanes. The location of aft tails was sometimes a factor. There were occasions where the horizontal tail was placed high relative to the wing plane in order to avoid the wing wake at low angles, or, sometimes to avoid locating the tail near the engine mountings or the jet flow field. Such high-tail designs resulted in the tail passing through the wing wake at some higher angle of attack, however, with a loss in tail effectiveness and a sharp pitch-up tendency. The pitch-up tendency was generally aggravated by aft center-of-gravity locations that accompanied rear-engine designs and promoted a more severe destabilizing effect from the lift of the long, slender, forebodies with increasing angle of attack.

Directional stability.- While the longitudinal traits of supersonic designs initially produced a problem of too much stability, the directional traits of the early designs produced a problem of insufficient stability. This trait is illustrated in figure 8 by the variation of $C_{n_{B}}$ with $M$ at $\alpha=0^{\circ}$ for a typical supersonic airplane with and without a vertical tail. The variation of $C_{n_{\beta}}$ with the vertical tail off is generally invariant with $M$ and is usually a function of the body geometry and the center of gravity location. The contribution of the vertical tail in providing for directional stability generally increases at subsonic speeds and decreases at supersonic speeds in a manner that essentially follows the lift-curve slope variation with $M$ for the vertical tail. The initial problem with directional stability at supersonic speeds occurs when the level of instability for the wing-body is large (generally due to aft center of gravity) and the lift-curve slope of the vertical tail decreases to the point where most of the tail contribution is required to offset the instability of the wing-body and little tail contribution remains to provide positive stability for the complete airplane. The problems of directional stability are further aggravated with increasing angle of attack. This is depicted in figure 8 by the variation of $C_{n_{B}}$ with $\alpha$ for a subsonic airplane and a supersonic airplane. For typical subsonic airplanes, the tail-off instability is generally less severe because of a more forward center of gravity. Thus, a greater portion of the vertical tail contribution is providing positive stability for the complete configuration and any loss in tail effectiveness that might occur due to adverse flow fields generated with increasing $\alpha$ are not necessarily critical. For the supersonic airplane, however, the tail-off instability may be substantial because of generally far-aft center of gravity locations and long, slender, destabilizing forebodies. 
Thus, a large portion of the vertical tail contribution is used simply in overcoming the instability of the wing body and any loss in tail contribution due to adverse flow at higher $\alpha$ subtracts directly from the directional stability level of the complete airplane. Note that static instability for the complete airplane may occur under these conditions even though the vertical tail contribution, per se, may be large. It is also important to remember that under these conditions, small losses in tail contribution (such as aeroelastic effects) may also lead to directional instability.

Control effectiveness.- The general problem of reduced control effectiveness at high speed has already been briefly mentioned. Some of the problems discovered early in the high-speed studies are illustrated in figure 9. The rapid decrease in pitch effectiveness of the conventional elevator control as transonic speed is approached results primarily from shock-induced separation near the control. This condition lead to the use of the all-moving tail for pitch control which, as indicated in figure 9, results in a substantial increase in control power. The variation in $C_{m_{\delta}}$ with $M$ for the all-moving tail is associated primarily with the lift curve slope variation for the tail.

A roll control problem with conventional aileron control was also discovered near the transonic range. As illustrated in figure 9, the problem consisted of a rapid loss in $C_{l_{\delta}}$ as the transonic region was approached and often resulted in a complete loss, or even reversal, of roll control. This loss in effectiveness was also caused by shock-induced flow separation over the ailerons for the relatively thick airfoil sections being used. Initial corrective steps to alleviate the problem included reducing the surface slopes for the aileron (blunt trailing edge) so that local shocks and flow separation effects were reduced (fig. 9). Soon, however, differential deflection of the all-moving horizontal tail was adopted as an effective way of dramatically increasing the roll control power.

Lateral characteristics. - Another aerodynamic trend found to be related to supersonic flight is the variation of effective dihedral with angle of attack, $C_{l \beta_{\alpha}}$, as shown in figure 10. Early theoretical calculations, and subsequent experimental work, showed that this parameter changes from a negative value (positive effective dihedral) to zero or slightly positive values (negative effective dihedral) when the wing leading edge becomes sonic. This condition occurs almost exactly for the 57 -degree delta wing airplane shown in figure 10 and results from the change in wing panel lift curve slopes with $\beta$ as the receding wing panel becomes subsonic and the advancing wing panel becomes partially supersonic. Such a characteristic results in changes in the roll-to-yaw ratio as a function of Mach number.

Dynamic pressure fields.- One other significant characteristic of supersonic aerodynamics that should be noted is the change in local dynamic pressure fields that occur. The effect is illustrated in figure 11 where the ratio of local dynamic pressure to free-stream dynamic pressure as a function of $M$ is shown for a lifting airfoil surface. In the upper surface flow field (expansion), the local q is substantially reduced whereas the lower surface flow field (compression) shows a significant increase in local q. Not only do these $q$ changes affect the lifting surface itself, but also the characteristics of any other part of a vehicle located in the flow fields induced downstream. The effectiveness of an aft tail, for example, could be seriously impaired if located in the upper surface flow field or considerably enhanced if located in the lower surface flow field. 


\section{Advent of the Supersonic Fighter}

An illustration of the evolution of the World War 11 fighter to the first generation of supersonic fighter is shown in figure 12. The progression from a subsonic propeller airplane, to a subsonic jet, and to a supersonic jet, show the geometric changes that have been discussed. Most noticeable is the overall increase in size, the lengthening of the body, the rearward shift in center of gravity. Note that little change occurs in the tail moment-arm but that a significant increase occurs in the length of the potentially destabilizing forebody.

\section{The Flight Research Airplanes}

The X-series airplanes.- Concurrent with the analytical and experimental model studies of high-speed flight, there was also some thinking in the early 1940's of a manned-airplane flight research program as an acknowledged way of obtaining accurate full-scale data in the transonic and supersonic speed regimes. Such an airplane was conceived at NACA-Langley in 1943 at about the same time that others in industry and service laboratories were harboring similar thoughts. These studies expanded and, in March 1944, results were presented at a seminar attended by personnel from the Army, Air Force, Navy, and NACA. The NACA proposed that a jet airplane be built specifically for the purpose of transonic flight research, and, with a government decision to undertake such a program, the X-series of research airplanes was born. On the basis of wartime NACA research, together with captured German research data, four major approaches to the problem of high-speed flight were chosen: thin wings, swept wings, low-aspect-ratio wings, and high-speed wing profiles. Both rocket and turbojet propulsion were to be considered. Airframe contractors involved initially were Bell and Douglas. The Air Force, working with Bell, was to handle thin wings and wing sweep. The Navy, working with Douglas, was to handle low aspect ratio and wing sweep. The NACA was to handle special wing profiles and to continue to provide basic research information of various types. The initial concepts were the BeIl XS-1 and $X S-2$ (subsequently the " $S$ " was dropped), the Douglas D-558-I and D-558-II, and the Douglas $X-3$. Soon to be added to the program for manned transonic and supersonic flight were the Northrop X-4; Convair XF-92A; Bell X-5; and Bel1 X-15. Bell Aircraft Corporation had begun work on the design of experimental high-speed airplanes in 1943. A contract was awarded to Bell by the Air Material Command in early 1945, and design and construction proceeded.

The Bell X-1 airplane.- The Bell XS-1 was the first of the new experimental a irplanes to be completed. It was a rugged design (load factor of 18) and used a proven Reaction Motors 6000-pound thrust rocket motor with a pressurized fuel system that provided for only about two and one-half minutes of powered flight. Because of the limited powered flight time, it was decided to air-launch from a B-29. The first glide flights were made over Pinecastle, Florida in early 1946, and the first powered flights were made in December 1946. The flight program was moved to the Army Air Force flight test area at Muroc Dry Lake, California, where seven miles of hard, dry lake bed runway lengths were provided. Then on October 14, 1947, the Bell XS-1, piloted by Air Force Captain Charles E. Yeager, broke the sound barrier for the first time by reaching $M=1.06$ on its ninth powered flight. It was the first of many supersonic flights for a family of $X-1$ airplanes and the age of supersonic flight was begun. Because of the pioneering achievement, the Collier Trophy for 1947 was awarded to John Stack (NACA), Lawrence D. Bell (Bell Aircraft), and Air Force Captain Yeager. Among other events in the $X-1$ series were: 
$0 \quad X-1, M=1.5$ on March 1948.

$0 X-1 A, M=2.4$ and 90,000 feet on December 12, 1953.

o X-1E, $1400 \mathrm{mph}$ and 73,000 feet with 4 percent wing, 1955.

o $X-1 B, 1600 \mathrm{mph}$ and 90,000 feet with reaction controls; used for thermal studies, 1954-1956.

o X-1D, destroyed during test on August 23, 1951.

The Bell X-IA is shown in figure 13.

The Douglas D-558-I airplane.- The Navy sponsored D-558-I Skystreak, the second of the flight research airplanes to fly, had a low aspect ratio, straight wing, and was powered by an Allison 5000-pound turbojet engine. The Skystreak began flying in early 1947 and established a world speed record of $650.8 \mathrm{mph}$ on August 25, 1947.

The Douglas D-558-II airplane.- The third research airpl ane to fly (1949), the D-558-II Skyrocket, had a 35-degree swept wing and was originally powered both with a Reaction Motors rocket and a Westinghouse J-34 turbojet for added takeoff and $\mathrm{climb}$ power. Three of these airplanes were built and one of them, with the turbojet removed, was air-launched, and with rocket power, became the first airplane to exceed $M=2$. Skyrocket events included:

$M=1.86$ on August 7, 1951 piloted by Bill Bridgeman.

$M=2.01$ on November 20, 1953 piloted by Scott Crossfield.

The Skyrocket also revealed the reality of the cross-coupling, pitch-up, wing-drop, and control effectiveness loss in flight at supersonic speeds.

The Northrop $X-4$ airplane.- The $X-4$ was the next research airplane, beginning to fly in the 1948-1949 era. The Northrop $X-4$ was a special Air Force project utilizing a swept-wing, tailless design, to examine the stability and control characteristics at transonic speeds on the premise that elimination of the horizontal tail would relieve some of the transonic problems associated with more conventional wing-tail combinations. The airplane became a reliable test bed for the study of pitch-up but never exceeded a Mach number of about 0.94 .

The Consolidated Vultee XF-92A airplane.- This airplane, a 60-degree delta tailless concept with a nose inlet supplying air to a 5200-pound thrust Allison $\mathrm{J}-33$ turbojet, was conceived as a prototype for an advanced Air Force fighter interceptor. It was added to the flight research program in 1951 for the study of the delta-wing concept for easing the problems of high-speed flight. The airplane was barely supersonic in a dive but was used extensively in obtaining information that was helpful in the future development of the $F-102 / F-106$ and the $B-58$.

The Bell X-2 airplane.- Conceived as a part of the original research airpl ane program, the Bell $X-2$ was designed for speeds up to $M=3$ at 100,000 feet. Because of the expected heating problems, the airplane was made of K-monel and stainless steel. The airplane had a 42-degree swept wing and was powered by a throttleable Curtiss-Wright rocket motor of 15,000 pounds thrust. Because of production difficulties, the supersonic flight program was delayed until 1955. In the summer of 1956, with Air Force Lt. Col. Frank Everest, Jr. at the controls, the airplane did 
achieve a speed of $M=2.8$. A few weeks later, Captain Ivan Kincheloe took the airplane to an altitude of 126,000 feet. On September 27, 1956, Captain Milburn Apt took the $X-2$ on its final flight and achieved a speed of $M=3.2$, marking another major step forward in supersonic flight. Two $X-2$ airplanes were built but it was a shortlived program, marred by the loss of both airplanes and two pilots. The airplane crashed September 27, 1956 while executing a rolling pull-up near $M=1.6$. An increase in sideslip angle, apparently resulting from loss of directional stability, lead to a structural failure of the vertical tail and destruction of the airplane. The possibility of such an occurrence was indicated in wind-tunnel tests made in 1948-1949.

The Douglas $X-3$ airplane. - The $X-3$ Stiletto was originally designed to explore the problems of sustained supersonic flight. The extremely long needle-nosed airplane had small tapered wings and was powered by two Westinghouse J-34 turbojets. The airplane first flew on October 20, 1952 and proved to be overloaded and underpowered. The airplane was barely capable of supersonic flight, achieving $M=1.1$ in June 1953. The inertia characteristics of the airplane were quite different from most all of its predecessors, but the airplane, with experienced pilots, remained operational until 1956 in the study of inertia coupling. The mass distribution of the airplane was essentially strung out lengthwise and was about zero in the spanwise direction. This made the airplane a prime candidate for the cross-coupling phenomena wherein pitch oscillations begin to feed into yaw oscillations, and vice versa, so that motions difficult to control might occur. Data derived from this design were used in programs such as the Lockheed F-104 and North American X-15. As a sidelight, the problem of inertial coupling had been studied in theory and reported by NACA Langley in 1948, but little attention was paid to the report until the flight problems occurred later.

The Bell X-5 airplane.- A subsequent addition to the flight research program was the BeTl $X-5$ variable wing-sweep airplane. Earlier analytical and experimental studies, based mainly on German work, had indicated the advantages of wing swept for high speed airplanes. Bell aircraft modified a P-63 airplane to incorporate a fixed sweep wing. Designated the L-39, the airplane was flight tested at NACA Langley late in 1947. Some stability problems were indicated, particularly at high lift, and as a result, the airplane was modified by the addition of four feet in tail length, a large ventral fin, and various wing leading-edge devices. In order to attain the desirable features of sweep for high-speed flight without the apparent low-speed stability problems, the thought of a variable wing-sweep airplane occurred at several places. In 1946 and 1947, low-speed wind tunnel tests of swept-forward and swept-back wings were conducted at NACA Langley. In July 1948, Bell submitted a proposal to the Air Force for a variable sweep research airplane. NACA concurred with the proposal and the $X-5$ became a part of the flight test program. The airplane first flew on June 20 , 1951. The wing sweep was variable in flight from about 20 degrees to about 59 degrees. As the wing was swept rearward, it was also translated forward in order to achieve a more consistent stability level. The airplane was barely capable of sonic speed (about $M=1.1$ ) but was used extensively in the study of gust response at low altitude with the wing fully swept. Such information was, of course, to become useful later in the decade when variable sweep tactical fighters were conceived. The Navy and Grumman did embark on the development of the XFIOF-1, a variable-sweep, translating-wing fighter. Extensive tests were made at NACA Langley in subsonic and transonic tunnels and also with rocket models. The prototype airplane first flew in May 1952, and although the variable-sweep wing feature was operated successfully, the project was cancelled primarily because the power from the West inghouse J-40 turbojet was insufficient for the needs of the airframe drag and some stability problems were evident. 
The North American $X-15$ airplane. - The last of the $X$-series high-speed research airplanes, the $X-15$ hypersonic airplane, had its origin in a document from Bell Aircraft January 8, 1952. The document included a proposal for a manned hypersonic research airplane to explore the basic problems of hypersonic and space flight. In June 1952, the NACA Committee on Aerodynamics recommeded an extension of the flight research program for the speed range from $M=4$ to 10 and altitudes to fifty miles. By the end of 1954, the NACA, Air Force, and Navy had signed a memorandum of understanding for a "Joint Project for a New High-Speed Research Airpl ane." Invitations for proposals were sent to industry December 30, 1954. In June 1956, a contract was awarded to North American for three $X-15$ airplanes and to Reaction Motors/Thiokol for the 57,000 pound thrust, throttleable, liquid rocket engine. Wind tunnel tests at NACA began in 1956 (fig. 14); construction of the airplane began in September 1957; the first glide flight was made in June 1959; the first powered flight was made September 17, 1959 (twenty-four years ago). NASA (by then renamed from NACA) began to fly the $X-15$ in March 1960 (fig. 15). The $X-15$ program explored many areas of technology in materials; structures; piloting techniques including use of reaction controls and effects of gravity ranging from zero $g$ to high-g reentry; propulsion; stability and control. A maximum speed of $M=6.7$ (0ctober 1966) and an altitude of 354,200 feet were achieved during the course of the flight program which extended from 1959 to 1968 with a total of 199 flights. There were plans to extend the program with a modified airplane to explore hypersonic cruise but development del ays, high costs, and the loss of the number three airplane in a reentry accident, led to the cancellation of the $X-15$ program and the end of an era in November 1968 .

\section{The Century Series Era}

In the latter 1940's, various airplane designs intended for supersonic flight were underway. The translation of research data, both wind tunnel and flight, into operational military airplanes was almost simultaneous. Airplanes such as the MCDonnel1 XF-88, Republic XF-91, and Douglas XF4D-1 Skyray were beginning to point the way toward a new generation of supersonic fighters. The new generation began to emerge in the 1950's and were dubbed the "century" series of fighters when the numerical designations reached 100 .

The North American F-100.- Fol lowing a company line of fighters that included the P-51 Mustang and F-86 Sabre, the F-100 Super Sabre became the first operational USAF airplane capable of sustained, level, supersonic flight (about $M=1.3$ ). The YF-100A prototype first flew May 25, 1953; the first production airplane flew in October 1953; 2,294 various models were built; production ended in 1959. The early models of the F-100 experienced some problems of inertia coupling and insufficient directional stability, and several airplanes and pilots were lost, including North American senior test pilot George Welch. Additional wind tunnel tests at NACA Langley confirmed the need for increased directional stability at angle of attack and a new vertical tail with a 27-percent area increase was put on the airplane. A twoseat version, the F-lOOF, is shown in figure 16.

The McDonnell F-101.- Following the design of the F-88, the F-101 Voodoo was the first USAF twin engine, supersonic fighter-interceptor airpl ane, having a speed capability of about $M=1.6$. The prototype first flew September 29, 1954 and production between 1957-1961 consisted of a total of about 800 airplanes (including all versions). The design was characterized by nozzles located forward of the tail portion of the airplane rather than at the base of the airplane. Part of the rational for such an arrangement is to keep the engine-associated weight (and airplane center of gravity) more forward, and to reduce the duct flow losses by shortening the duct 
length. A consequence of the arrangement, however, is that the afterbody and tail regions are subjected to the jet exit flow. Accordingly, heat protection of the afterbody must be considered as well as the location of the horizontal tail. The high tail location used on the F-10l is a contributor to pitch-up instability. The F-101 design was the subject of wind tunnel and rocket-model tests by NACA Langley in 1955 in order to determine the stability and control boundaries.

The Convair F-102.- The F-102 Delta Dagger was an outgrowth of the XF-92A fighter-interceptor research airplane. The airplane first flew 0ctober 24, 1953 but showed no hope of reaching its supersonic design speed and was barely able to penetrate the transonic range. Accordingly, extensive studies were undertaken to improve the interceptor performance. Among the subsequent modifications, based on NACA Langley research, were the application of the transonic area rule that resulted in a "coke bottle" fuselage to reduce the transonic drag rise penalties; a new wing design with a conically cambered leading edge and reflexed wing tips to improve the drag. due to lift characteristics; a new vertical tail location to improve the supersonic directional stability level; and a total extension in fuselage length of eleven feet. The modified airplane, nicknamed the Hot Rod, first flew on December 19, 1954, reaching a Mach number of 1.22 at an altitude of 53,000 feet. The first production F-102A flew June 24, 1955 and the airplane entered operational service in April 1956. The production ended in July 1958 with a total of $889 \mathrm{~F}-102 A^{\prime} \mathrm{s}$ and $111 \mathrm{TF}-102 \mathrm{~A}$ trainers with side-by-side seating.

The Lockheed F-104.- The F-104 Starfighter prototype first flew February 7, 1954 and over 2500 were built between 1955-1977. With the exception of about 300 airplanes, the F-104 was exported to other countries. The F-104A set a speed record of $M=2.1$ on May 18, 1958 and an altitude record of 103,395 feet on December 14, 1959 and, for a time, simultaneously held the world records for speed, altitude, and timeto-climb. Along with the remarkable performance, the F-104 also had problems in the form of cross-coupling (due to the inertia distribution) pitch-up (due to the tail location), and low directional stability at high $M$ and high angle of attack (due to the inherent instability of the long body and other geometric constraints). A modification made as a result of NACA wind tunnel tests was the addition of a fairly effective ventral fin to improve the directional stability.

The Republic F-105.- Foll lowing the lineage of the P-47 Thunderbolt; F-84 Thunderjet; F-84F Thunderstreak; the F-105 Thunderchief, supersonic fighter-bomber began flying in October 1955 and went into service in May 1958. For a while, the airplane held the 100-kilometer speed record of $M=1.8$. The original design of the F-105 did not incorporate the transonic area rule. However, the early wind tunnel tests made in the Langley 8-foot transonic tunnel indicated that substantial drag improvements could be realized through the application of some body contouring and the modification was made to the third airframe. In addition, the original transonic inlet was changed to a supersonic inverted scoop inlet as a result of NACA tests. Other modifications made as a result of NACA Langley wind tunnel tests were an enlarged vertical tail and the addition of a ventral fin to enhance the supersonic directional stability.

The Convair F-106.- An outgrowth of the F-102 Delta Dagger configuration was an advanced interceptor originally designated $F-102 B$ that was subsequently redesignated the F-106 Delta Dart. The F-106 is similar in appearance to the F-102 with perhaps the most noticeable external difference being a change in vertical tail planform from a near-delta shape to a larger area trapezoidal shape that was made to improve the directional stability. The F-106 had a more powerful engine, increased payload, increased range, and speed (slightly in excess of $M=2$ ). The F-106 first flew 
December 26, 1956 (about 3 years following the F-102) and became operational in October 1959. Production ended in December 1960 with a grand total of about 340 F-106's of all types having been built. With an average age of over 23 years, the F-106 is now being relegated to the Air National Guard.

Other century designs.- Other "century" designated designs that will be briefly mentioned are the Republic XF-103 experimental interceptor that incorporated a variable-incidence wing and a combined turbojet/ramjet propulsion scheme. The airplane, intended for $M=3 \mathrm{flight}$, was cancelled. The North American F-l07A, $M=2$ follow-on fighter bomber to the $F-100$, had a sharp pointed nose, a top-inlet aft of the cockpit, and an all-moving vertical tail. Three of the airplanes were built with the first flight on September 10, 1956. Although the airplane repeatedly flew to $M=2$ and provided useful flight information, it was never put into production. The North American XF-108 Rapier design was the winner of a contract in 1957 for an advanced, long-range, $M=3$ interceptor. The Air Force had programmed for about. 480 aircraft to become operational by 1963. After reaching the mock-up stage the program was cancelled due to funding problems in September 1959. The Bell XF-109 was designed to be a $M=2.3$ interceptor with VTOL capability provided by means of four wing-tip rotatable jets and two direct-lift engines mounted in the fuselage. Additional forward thrust would be provided by two engines conventionally mounted in the aft fuselage. A mock-up was built in 1961 but the actual aircraft was never constructed. The F-110 was the USAF designation originally given to the F-4 when the airplane was first adapted from the Navy. The F-111, which was the last of the 100 designations, and the F-4 (F-110) will be briefly discussed later.

Other airplanes of the century era.- Certain other U.S. high-speed airpl anes not related to the so-called "century" series by numerical designation, but evolving in the same time period (1950's), that might be noted are:

- Douglas F4D-1 Skyray, first flew in January 1951 and once held the $100 \mathrm{kilo-}$ meter closed-course record near $M=1$.

- Convair XF2Y-1 Sea Dart, a hydroski (waterbase) Navy delta wing fighter similar to the XF-92A and F-102. First flew in April 1953 but was cancelled.

- Grumman F11F-1 Tiger, first airplane to be designed using the transonic area rule concept. Demonstrated relative ease in negotiating the transonic range, first in July 1954, using about 25 percent less thrust than required by the F-100 or F4D. Only a limited number of F1IF-l's and F1IF-1F Super Tiger's were procured. The airplane was used by the Blue Angels and had only a 1 imited fleet assignment.

- Chance Vought F8U-1 Crusader first flew in March 1955. The airpl ane featured an underslung chin-inlet and had a variable-incidence wing. The airplane, and its follow-on models, were ordered in quantity and assigned to the fleet. It was apparently chosen over the FllF perhaps because of its large size and load-carrying capability.

- Convair B-58 Hustler was the first U.S. supersonic $(M=2)$ operational bomber. Following the Convair fighter tradition, the B-58 was area-rul ed and had a delta wing with conical camber and elevon control. Four podded engines were used and the payload (and some fuel) was carried externally in a large droppable pod beneath the body. The first supersonic flight was on December 30 , 1956. The USAF ordered 136 Hustlers that were operational with SAC between 1960-1970. The B-58 set 19 world records (speed and altitude) including a 
round trip Los Angeles-New York flight March 5, 1962 that broke three speed records and, reportedly, also broke several windows, thus giving the American public an awareness of the sonic boom problem. Some B-58 problems surfaced when vertical tail structural failure occurred in sideslip during asymmetric engine-out flight at supersonic speeds. A region of low directional stability appeared to be further aggravated by control-induced adverse yaw.

- North American A-5 Vigilante was the first seaborne medium-sized nuclear bomber with supersonic speed capability of about $M=2$. The airplane was a high-wing, two-seater, twin-engine type with twin horizontal-ramp, variablegeometry inlets to feed two J-79 turbojets. The design employed a unique bomb ejection system that was to release the bomb out the rear of the airplane. The original prototype, designated YA3J-1, flew August 31, 1958. The designation was changed to $A-5 A$ in 1962. The mission was changed to reconnaissance and the first RA-5C flew in 1962 and went into fleet service in January 1964. Altogether, about 156 were constructed.

- Northrop T-38 Tal on was the first supersonic airpl ane designed for the training mission. It was derived from a company project, the N-156, that was used to develop an affordable supersonic fighter primarily for export. The fighter version became the F-5A Freedom Fighter with later versions up to the F-5E Tiger II. A small, lightweight airplane, the trainer version exceeds $M=1.2$ and the fighter version exceeds $M=1.6$. The $T-38$ first fl ew April 10, 1959 and more than 1100 have been built. About 900 are assigned to the USAF including a few for the Thunderbirds. The first F-5 flew July 3 , 1959 and nearly 2000 have been built. The airplane has been supplied to about 16 countries with very few used by the U.S. It is interesting to note that the primary assignment of U.S. F-5's are about 55 airplanes to four USAF aggressor squadrons and about 13 airplanes to one Navy aggressor squadron where, as reported in the open press, in the role of an aggressor in air combat, the F-5 has performed very well against modern U.S. operational

fighters.

- McDonnell F4H Phantom, originally developed as a Navy shipboard fighter, first flew on May 27, 1958. Wind tunnel tests in the late 1950's revealed that the original $\mathrm{F} 4 \mathrm{H}$ design had some of the characteristics of its ancestors. Several modifications made to the production design were the sharply drooped tail panels to alleviate pitch-up; outboard wing leading-edge extensions to improve the high-lift stability; and turned up wing-tip panels to improve the roll/yaw ratio. In 1963, the airplane was procurred by the USAF as a tactical fighter originally designated by USAF as $F-110$ and, through many modifications, the airplane remained in production as the F-4 for over 2 decades.

\section{Other Supersonic Military Airplane Programs}

In late 1954 a military requirement, WS-110, was proposed for a sustained supersonic cruise strategic bomber to replace the B-52. It was to operate from existing runways, cruise unrefueled for at least 6000 nautical miles, and have a $M=3$ capability at altitude. The North American XB-70 Valkyrie proposal was eventually chosen and two airplanes were built for flight research. The first $X B-70 \mathrm{flew}$ on September 21, 1964 and achieved $M=3$ on October 14, 1965. The second $B-70 \mathrm{flew}$ on July 17, 1965 and was destroyed on June 8, 1966 in a midair collision with an F-104 chase airplane. The XB-70 was designed to make use of the "compression lift" generated 
beneath the wing by the wedge-shaped sides of the engine ducts. Unfortunately, additional drag was also generated and efficient lift-to-drag ratios for cruise were problematical. The $X B-70$ was designed so that the wing tips could be drooped to 65 degrees which, at supersonic speeds, would improve the directional stability. The the concept of mixed ICBM's and B-52's as strategic deterrents.

Reconnaissance.- One of the best kept secrets in the U.S. was the Lockheed A-11 developed by Kelly Johnson and the "skunk works" team as a high-altitude, $M=3$ cruise reconnaissance airplane, follow-on to the subsonic $U-2$. Wind-tunnel tests were underway (some at NACA Langley) in the later 1950's and initial flight of the A-11 occurred April 26, 1962. The airplane was not publicly revealed until the spring of 1964. A fighter version, the YF-12, flew early in 1964 and the prototype SR-71 Blackbird prototype strategic reconnaissance airplane flew Uecember 22, 1964. Production airplane deliveries began in January 1966 for operation by the $9 \mathrm{th}$ Strategic Reconnaissance Wing at Beale Air Force Base, California. The airplane, at various times, has held several world records for speed and altitude. In September 1974, an SR-7I flew from New York to London in one hour and fifty-five minutes at an average speed of about $1807 \mathrm{mph}(M=2.7)$. In July 1976, the SR-71 set records of $2193 \mathrm{mph}(M=3.3)$ over a straight course, $2092 \mathrm{mph}(M=3.1)$ over a $100 \mathrm{~km} \mathrm{closed}$ course, and a sustained level-flight altitude of 85,069 feet. About 30 airplanes are believed to have been built.

Multimission tactical fighter.- On November 24, 1962, the U.S. ushered in a new era of tactical fighters with the initial development contract to General Dynamics/ Grumman for the TFX (F-111), two-place, twin-engine, variable-sweep, tactical fighter multimission airplane. The missions were to include $M=2.5$ capability at altitude, $M=1.2$ penetration at sea level, ferry range of $3600 \mathrm{miles}$, with operation from rough fields on 3000-foot strips. It was originally estimated that $1500 \mathrm{~F}-11 l^{\prime} \mathrm{s}$ would be built at a total cost of 4 to 5 billion dollars. General Dynamics was to develop the USAF fighter and Grumman was to develop the Navy F-111B shipboard fighter. Initial NACA work leading up to the TFX contract began as early as 1945 with wind tunnel tests of swept and yawed wings. Variable sweep was proposed with tunnel tests of a modified $X-1$ in 1947. By 1948, the Bell $X-5$ variable sweep airplane was conceived. In 1952, the Grumman YF10F flew with a translating, variable-sweep wing but failed due to problems not associated with the wing. NACA studies in the later 1950 's showed the potential of variable sweep for combining supersonic capability at altitude with good subsonic range; good low-speed landing and takeoff; alleviating gust loads to provide high-speed penetration at low altitude; and increasing loiter time. In 1959, studies included the British Vickers Swallow, a variable sweep proposal for sustained $M=2$ flight, and various ensuing research models that lead to a wing pivot location that minimized stability variations with sweep without the necessity of wing translation. A combat air patrol (CAP) variable sweep concept was proposed to the Navy; a tactical fighter was proposed to USAF/TAC; a proposal was made to the Navy to modify the $A 3 \mathrm{~J}$ to a variable sweep wing; and industry was briefed on the variable sweep concept--all in 1959. By 1960, USAF/TAC dropped their work on a VTOL requirement and adopted the variable-sweep STOL concept. During 1960, NASA-Langley conducted extensive reseach on the TAC series of models. These studies included what was known as project "Hurry Up" wherein three concepts (TAC 7, 8 and 9) were designed, constructed, tested, and data was available in 13 days. In February 1961 , Secretary of Defense McNamera ordered that the requirements of USAF, Navy, and Army be combined into a tri-service tactical fighter. Proposals for the design of TFX were sent to industry in September 1961 and the evaluations began at USAF/ASD December 4, 1961 with USAF, Navy, and NASA participation. Respondents were Boeing, General Dynamics/Grumman, Republic/Chance Vought, Lockheed, McDonnell/Douglas, and 
North American. Boeing and General Dynamics were selected as Phase I winners on January 31, 1962 and were given sixty days to continue their studies. Phase II evaluation began April 1, 1962 with some deficiencies noted by the Navy with regard to buffet and carrier compatibility. Phase III evaluation began June 14, 1962 with Boeing and General Dynamics again given a sixty-day extension. Phase IV evaluations began September 10, 1962 and the Phase $V$ final evaluations took place September 24-28, 1962. Two months later, November 24, 1962, Secretary McNamera announced the contract award to General Dynamics/Grumman, thus beginning a period of technical and political difficulties that were to last for years. The political hearings began in 1963 by the Senate's Permanent Subcommittee on Investigations of the Committee on Government Operations, under the chairmanship of Senator John McClellan, in response to Senate suspicions that the award to General Dynamics was politically motivated. As for the development of the airplane, some problem areas surfaced in inlet/engine performance, stability and control, weight increase, and so on. The first airplane flew on December 21, 1964 and the delivery of operational airplanes began in 0ctober 1967. Ten years later, when production ceased, only about 500 airplanes had been built (one-third of the original estimate) at about twice the originally expected cost. The Navy never procured any B models and cancelled its program in 1968. Subsequently, the Navy developed its own tactical fighter, the F-14, and the Air Force developed its own tactical fighter, the F-15. Somewhere multi-service commonality of a single airplane had failed. Some airplanes, having about a 7-foot increase in wing span, were designated FB-111 and assigned to SAC as strategic bombers in 1969. About 60 of these airplanes equipped with SRAM missiles are now in service.

Current generation fighters.- Beginning in the late 1960's and continuing into the 1970 's, a new generation of supersonic fighters came into being. The proposals were again conducted in concert with NASA--the FX program for the Air force and a VFAX program for the Navy. By 1969, Grumman was under contract to develop the F-14A Tomcat for the Navy--a two-place, twin-engine, variable-sweep, shipboard fighter. The prototype flew December 21, 1970 (six years to the day after the first F-111 flight). Operational F-14B's first flew in September 1973 and about 200 airplanes were in fleet service by the end of 1978. The Air Force F-15 finalists in 1969 were Fairchild Hiller, McDonnell Douglas, and North American. The contract was awarded to McDonnell Douglas for the single-seat, fixed-wing, twin-engine F-15A Eagle. The prototype flew July 27, 1972, production deliveries began in 1973, and more than 200 were in service by the end of 1978. Eight world time-to-altitude records were set in 1975 by a special F-15 Streak Eagle. In April 1972, USAF selected Northrop and General Dynamics to compete for the Lightweight Fighter Program. In January 1975, a contract for the lightweight, single-seat, single-engine, F-16 fighter was awarded to General Dynamics. The first prototype had flown in February 1974 and the first operational F-16's were delivered to USAF/TAC in January 1979. The airplane is also being produced for NATO use. The McDonnel 1 Douglas/Northrop F-18 Hornet first flew as a Northrop YF-17 prototype July 9, 1974. The single-seat, fixed-wing, twin-engine shipboard strike-fighter is now being developed for the Navy.

The Rockwell B-1.- The Rockwell B-1 variable-sweep, four-engine airplane was developed as a strategic bomber for both high-altitude cruise and supersonic flight as well as low-altitude high-speed penetration. Four airplanes were built with the first flight on December 23, 1974. The airplane exceeded $M=2$ in April 1976 and demonstrated high-altitude cruise and low-altitude terrain-following penetration. The airplane, which like the B-70, was the intended replacement for the B-52, also became entangled in technical and political problems and was cancelled by President Carter in June 1977. Subsequentiy, the program was reinstated by President Reagan in 


\section{Civil Supersonic Developments}

The SCAT program.- Although the main thrust in supersonic flight had been for military airplanes, some NACA attention was turned in 1958 to the development of a supersonic civil transport. A research program was begun at NASA-Langley in 1962 directed toward a Supersonic Commercial Air Transport, or SCAT. The purpose of the program was to develop the technology for an economically sound supersonic transport (SST) that would preserve the leading role of the U.S. in commercial air transportation. Many concepts were conceived and tested at Langley and, by early 1963, four SCAT configurations had been selected for detailed study:

- SCAT-4, a Langley fixed-wing proposal that carefully integrated the wing, fuselage, engines and tails into a highly-swept, cambered and twisted design intended to minimize the wave drag and the drag-due-to-lift.

- SCAT-15, a Langley proposal that originally employed a variable-sweep wing overlayed on a highly-swept fixed wing, and twin outboard vertical tails. The concept, with some modifications, was to become one of the foundation stones of the entire SST program--the SCAT-15F.

- SCAT-16, a Langley proposal with a highly-swept, variable-sweep wing with an inboard pivot.

- SCAT-17, an Ames proposal with a fixed 60-degree delta wing and a canard
control.

An industry study of the four configurations resulted in further concentration on SCAT-16 and SCAT-17. In a subsequent SST competition, Lockheed proposed a fixed, delta-wing design, and Boeing proposed a variable-sweep design. In the final evaluation, Boeing was selected to develop the first U.S. supersonic transport. In the ensuing years, the program met with technical, political, economical, and ecological problems, and in December 1970, the U.S. Congress reduced the funding that led to the cancellation of the program by March 1971. In the interim, the Soviet Union had proceeded with an SST design culminating in the flight of the world's first supersonic transport, the Tupolev TU-144 Charger, on December 31, 1968 (two years before the cancellation of the U.S. prototype development programs). The TU-144 has been used on some limited routes by Aerofl ot but is currently out of service. The French/ British also entered the SST program in the 1960's and the Sud-Aviation British Aircraft Corporation Concorde supersonic transport made its first flight on March 2, 1969. The Concorde has been used in commercial service between the U.S. and Europe. While advanced supersonic cruise technology research has continued in the U.S. on a limited basis, there is no supersonic transport development program in being today. It seems clear that the primary obstacles to such a program are largely nontechnical.

\section{Other World Developments}

Many developments toward supersonic flight were underway in various countries beginning at least in the 1940 era. World War II studies by the Germans and Italians have been mentioned earlier. During the 1940's and beyond, this work influenced programs in other countries by bolstering research and development al ready underway. A brief survey of some of these developments follows.

Great Britain.- The use of jet propulsion, which was to mark the way for supersonic flight, was boosted along by the work of Frank Whittle in Britain. While not 
the first to conceive of jet propulsion, Whittle, who began his work in 1930 at the (Unknown af finally saw the Gloster E28/39 fly with one of his engines on May 15, 1941. Heinkel He-178 with a Hans von Orsitz had flown the first jet-propelled airplane, the By the summer of 1944, the von Ohain designed engine, in Germany on August 27, 1939.) But even earlier in to develop a jet-propelled, the Miles Aircraft Company had been commissioned in 1943 feet after a dive from 50,000 feet. the M52, designed to fly at $1000 \mathrm{mph}$ at 36,000 the grounds that such flight was to In 1946, the government cancelled the project on fly the first supersonic airplane. airplane launched from the ground. However, the Fairey Delta 2 became the first built. The airplane was equipped to exceed $1000 \mathrm{mph}$ (1956). Two Fairey Delta's were improved forward vision. One of the a nose section that could be lowered to envisioned for the Super Caravelle or coming Concorde research vehicle and was a twin-jets mounted became a leading $M=2$-under in the afterbody first flew July 11,1961 and soon flying in 1965 and being fighter. The BAC TSR-2 strike-reconnaissance airplane was fighter for the 1970's. fighter. However, by 1967 , both interesting research airplane, the TSR-2 and the PI154 were cancelled. An 188 had an accommodate a variety of engines in flight near $M=2$. Supersonic British design
essentially disappeared after the $1960^{\prime}$ s and essentially disappeared after the 1960's and gave way to multinational ventures.

France.- By the mid 1950's the French were well along with some interesting highspeed designs. Among these were the Leduc 0.21 , an air-launched ramjet that first flew in August 1953, and the follow-on Leduc 0.22 with ground takeoff capability that flew in December 1956. The 0.22 was a combination ram-turbojet intended for flight in the $M=2$ to 4 range. There appeared to be a marked similarity in the design of the Leduc 0.21 and 0.22 to that of the British Miles M52.

Other French developments of the 1950's include the following airplanes.

- SE-5000 Baroudeur experimental interceptor which used a rocket-dolly for takeoff and landed on skids. It was reported to have flown near $M=1$ before
the project was dropped.

- S0-9000 and 9050 Trident had two wing-tip mounted jet engines in addition to a rocket motor and reportedly exceeded $1100 \mathrm{mph}$.

- Sfecmas 1402 Gerfaut experimental delta-wing fighter was reported to have
exceeded $M=1$ in August 1954 .

- Sud Super Vautour twin-jet supersonic bomber was cancelled in 1958 as it neared the prototype stage.

- Nord Griffon ramjet-turbojet delta-wing canard fighter. The Griffon, an outgrowth of the Leduc ramjets, flew in January 1957. The airplane flew at $M=1.8$ in a climb, and in 1959, won the Harmon trophy when test pilot Andre Turcat flew the Griffon 2 at $M=2.19$. Griffon 2 research was continued for a short period with the aid of a USAF research contract.

By 1960, the French supersonic airplanes included the Dassault Super-Mystere fighter-bomber, the Navy Etendard IV fighter, Mirage III tailless delta fighter, 
Mirage IV tailless delta two-place bomber, and Nord 1405 Gerfaut II. A Mirage $3 \mathrm{~V}$ $M=2$ VTOL fighter with direct-lift engines was also in flight test in 1965. The Mirage $3 G$ variable wing-sweep fighter was in design with plans for a future combination of the $3 G$ and the $3 V$ into a V/STOL, multimission, supersonic fighter.

Current French supersonic airplanes also include the Mirage Fl, Mirage 2000, Super Mirage 4000, and Mirage 5.

Other free-world countries.- Many countries have been involved in the development of supersonic airplanes. Some are noted here:

- Canada--Canadair CF-105 tactical-support fighter, 5 built, flew in 1958.

o Egypt (UAR)--Helwan HA-300 $M=2$ fighter.

- India--Hindustan HF-24 fighter, first flew June 16, 1961.

- Israel--Kfir C2 $M=2$ fighter.

o Italy--Aeritalla (Fiat) G. 91 fighter, $M=1$.

- Japan--Mitsubishi T-2 strike-trainer and $F-1$ strike-fighter, $M=1.6$.

- Sweden--Saab 35 Draken $M=2$ fighter, first flew October 1955. Saab 37 Viggen $M=2$ all-weather strike fighter, first flew February 1967.

Multinational airplanes.- Current multinational supersonic airplanes include:

- Panavia Tornado (MRCA) variable geometry, strike-reconnaissance fighter (Britain, Italy, Germany).

- SEPECAT Jaguar strike fighter (Britain, France).

- Concorde SST (Britain, France).

People's Republic of China.- Having gained experience by producing some Sovietdesigned fighters, the PRC has developed the Shenyang F-9 Fantan-A twin-engine supersonic fighter believed to be in service since about 1973. The airplane layout appears to be similar to the Soviet MIG-19 except for the twin-side inlets and the concial nose. Other concepts are believed to be under development.

U.S.S.R.- Supersonic airplane development in the U.S.S.R. has been fairly systematic and rather persistent since about the mid 1940's. In combination with native talent, Soviet aviation received a tremendous boost following World War II with technology and equipment from both the Allied and the Axis countries. About 1947, the Soviets were flying the swept-wing MiG-15, followed by the MiG-17 about 1950. These fighters pressed close to transonic flight and in the early 1950's, supersonic flight became a reality in the Soviet Union. The continuity of Soviet developments, both by airplane types (mission) and by design bureau, facilitates the following tracing of their history:

Mikoyan Design Bureau.- The design team of Mikoyan-Gurevich followed their subsonic fighter designs with a series of supersonic types. 
- MiG-19 Farmer was the first Soviet supersonic fighter flying by 1953. A swept-wing aft-tail concept with about $M=1.4$ capability.

- MiG-21 Fishbed, a delta-wing, aft-tail fighter with $M=2$ capability was flying by 1955. The MiG-2l is a good example of a small lightweight air combat fighter and, after more than twenty-five years, is stili being produced.

- MiG Ye-2A Faceplate was an experimental swept-wing, advanced Farmer-type that was flying about 1955 but was not produced.

- MiG Ye-152A Flipper was an experimental delta-wing fighter with twin engines but a single nose inlet. Flipper was in the 1961 Tushino fly-by but was never produced.

- MiG Ye-166 was a large, single-engine, experimental delta-wing design apparently used for high-speed flight research. The Ye-166 held several FAI records: $1492 \mathrm{mph}$ for 100-km closed course October 7, 1961; $1666 \mathrm{mph}$ for $15-25 \mathrm{~km}$ course July 7 , 1962; $1865 \mathrm{mph}(M=3)$ July 7 , 1962; sustained 1553 mph at 74,376 feet September 11,1962 .

- Faithless was a direct-lift engine experimental STOL airplane flown in the 1967 Domodedovo fly-by. - MiG-23 Flogger, a variable-sweep fighter first shown in 1967 and still being
produced in several versions.

- MiG-25 Foxbat, also shown in 1967 was the world's first operational $M=3$ fighter-interceptor reconnaissance airplane. Much was learned about Foxbat when Lt. V. Belenko flew one to Hakodate, Japan, September 6, 1976.

- MiG Ye-266, prototype for the Foxbat, has held several FAI records: $M=2.2$ for $1000 \mathrm{~km} \mathrm{closed}$ course with a 4400 pound payload March 16,$1965 ; M=2.8$ for $500 \mathrm{~km}$ course October 5, 1967; alt itude of 98,462 feet with a 4400 pound
payl oad October 5, 1967. O Other advanced MiG's are reportedly under development such as the MiG-29
Fulcrum.

Sukhoi Design Bureau.- Sukhoi has also contributed primarily to fighter-type airplanes.

- Su-7 Fitter strike fighter, a $M=1.7$ highly-swept wing, aft-tail airplane
was flying in 1955 .

- Su-9 Fishpot, a $M=1.8$ delta wing, aft-tail, all-weather fighter was also flying in 1955. Both the Su-7 and 9 flew by in the 1956 Tushino air show.

- Su-17, 20 are variable-sweep derivatives of the Fitter providing improved mission capability. The first version, Fitter $A$, was revealed in the 1967 air show.

- Su-15 Flagon A was first shown in the 1967 air show. A $M=2.5$ all-weather fighter interceptor. A Flagon B STOL prototype with direct-lift engines flew in the same air show. The Flagon A continues in production. 
- Su-24 Fencer is a $M=2.3$ variable-sweep, two-place, twin-engine strike fighter that was flying by 1968 and continues in production.

- Su-27 Flanker is an advanced supersonic fighter currently under development.

Al1-weather interceptors.- An all-weather interceptor compet ition initiated in 1948 has involved more than one design bureau. Initial subsonic competitors originally included Sukhoi, Yakovlev, and Lavachkin. These were narrowed down to the high-subsonic Yak-25 Flashlight by 1953. The supersonic airplanes that have followed in this category are:

- Yak-28 Firebar with limited supersonic capability. This airplane is distinquished by its two large podded engines beneath the swept wing and a bicycle-type landing gear with wing-mounted outriggers. A bomber version was code-named Brewer.

- Tu-28 Fiddler, a swept wing Tupolev design with twin-body mounted engines that was first shown in the 1961 air show. The airpl ane has about a $M=1.6$ capability and is still the world's largest interceptor airplane.

- It is believed that a new long-range interceptor with $M=2+$ capability is under development.

Bombers.- Again after a series of various bombers leading up to a high subsonic speeds, some supersonic developments appeared.

- M-52 Bounder was the world's largest supersonic airplane when first seen in the $1961 \mathrm{fly}$-by. Built by Myasishchev, the airplane had a delta wing with an aft-tail and four engines--two smaller podded engines on the wing tips and two quite large engines with afterburner, that were pylon mounted near the wing mid-semispan. The airplane had about a $M=1.4$ capability and, while not produced, undoubtedly gave the Soviets a wealth of information of the behavior of large supersonic airplanes.

- Tu-22 Blinder, the world's first supersonic operational medium bomber was shown in the 1961 air show. The Tupolev design has a highly swept wing (similar to Fiddler) and incorporates twin engines mounted at the base of the vertical tail. In a typical Tupolev fashion, the main gear is stowed in wing pods. In its prime mission as a Naval antishipping airplane, the Blinder carries the large AS-4 Kitchen missile semisubmerged in the bottom of the fuselage.

- Tu-26 Backfire, a Tupolev variable-sweep twin engine bomber first seen in 1969. The Backfire is a $M=2$ airplane at altitude and with its variablesweep wing has the added capability of high speed, low level penetration, as well as extended subsonic range. The original Backfire A had its main gear stowed in the familiar wing pods. On the production Backfire B, among other modifications, the main gear stowage was changed and the wing pods removed, apparently to reduce drag. The Backfire has been seen carrying the AS-4 Kitchen antishipping missile semisubmerged in the fuselage. It is also expected that the Backfire could carry two pylon-mounted AS-6 Kingf ish antishipping missiles. Modifications to increase the performance of Backfire are apparently continuing. 
- It is reported that other supersonic bombers are under development. A new variable-sweep type, the Tupolev Blackjack, which is about 40 percent larger than the Backfire, was first seen in November 1981. A fixed-wing type similar to the Tu-144 Charger may also be under development.

\section{CONCLUDING REMARKS}

Man's quest for increased speed in transportation has shown remarkable progress with the airplane since the advent of supersonic flight in 1947. While much of the progress has been for military systems, there have also been some achievements in civil systems. The major impetus for military systems has been related to achieving combat advantage or supremacy with, perhaps, slightly less thought to economics or safety. The major impetus for civil systems, of course, is more directly related to economics and safety. Many problems have arisen, many have been solved, some still remain. The sonic boom, for example, still appears to be an inherent problem of supersonic fijght that, in particular, affects overland commercial flight. Efforts cont inue for generally increased efficiency for economic and performance gains, and for increased safety, for both military and civil airplanes. Much has been done, yet much remains to be done. 


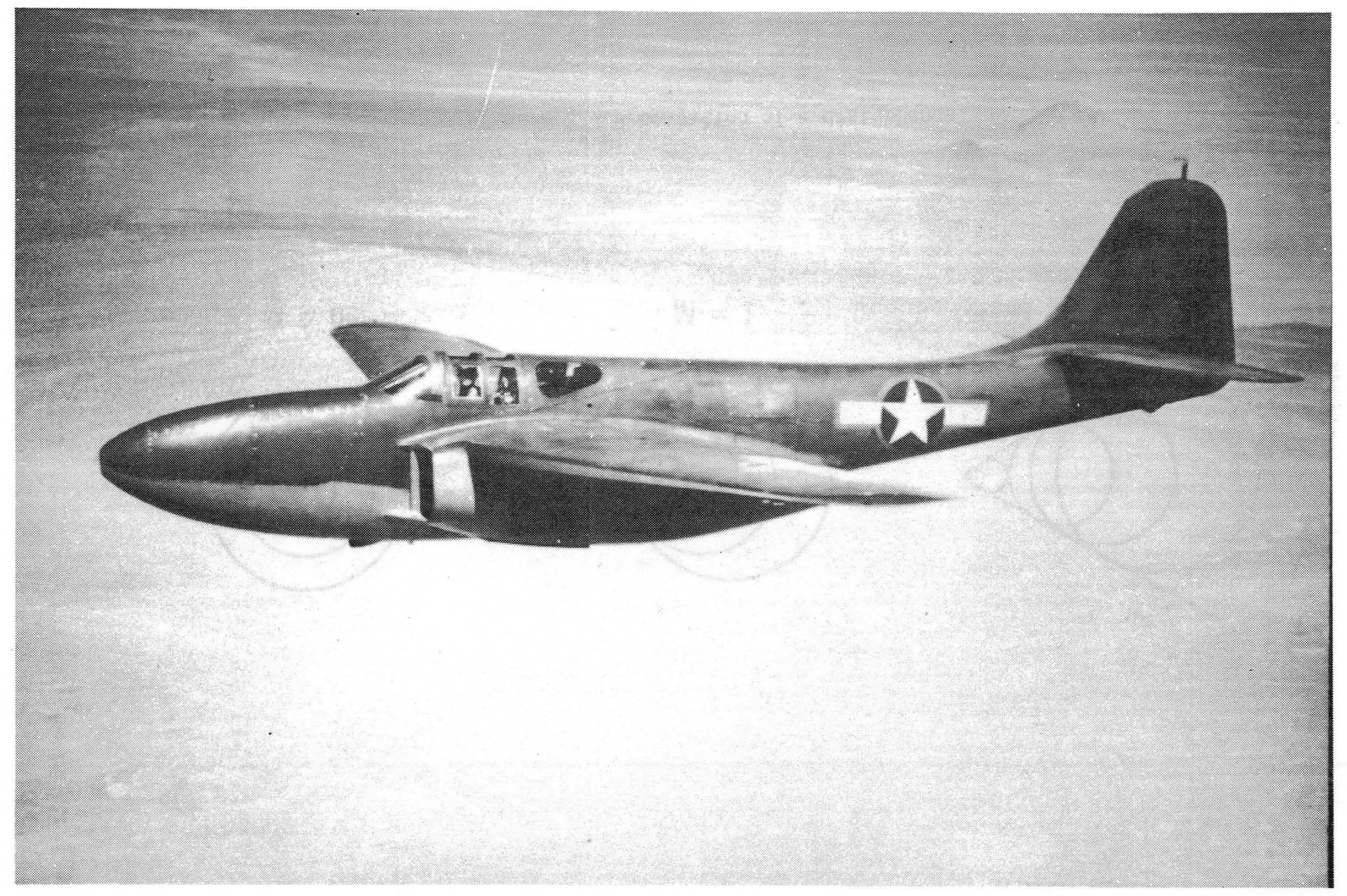

Figure 1.- The Be11 P-59 Airacomet, the first American jet. 


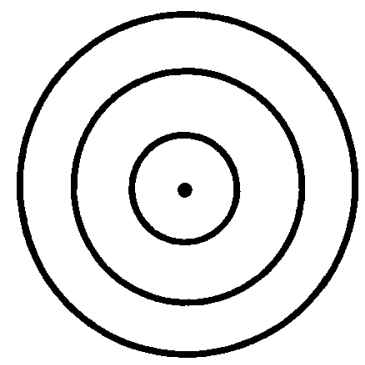

$M=0$

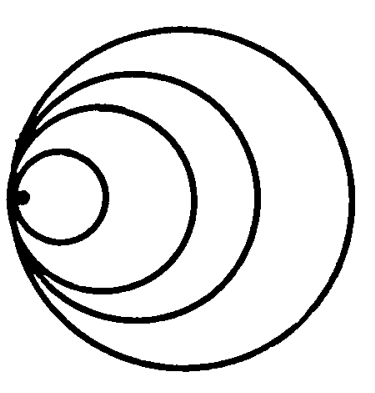

$M=1$

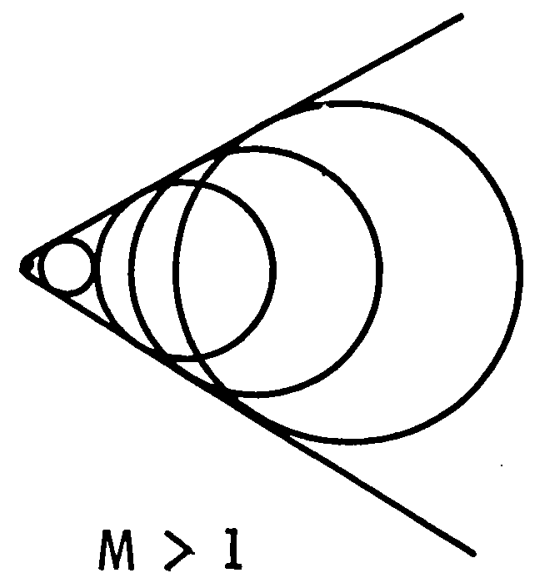

$M>1$

Figure 2.- Propagation of a disturbance. 

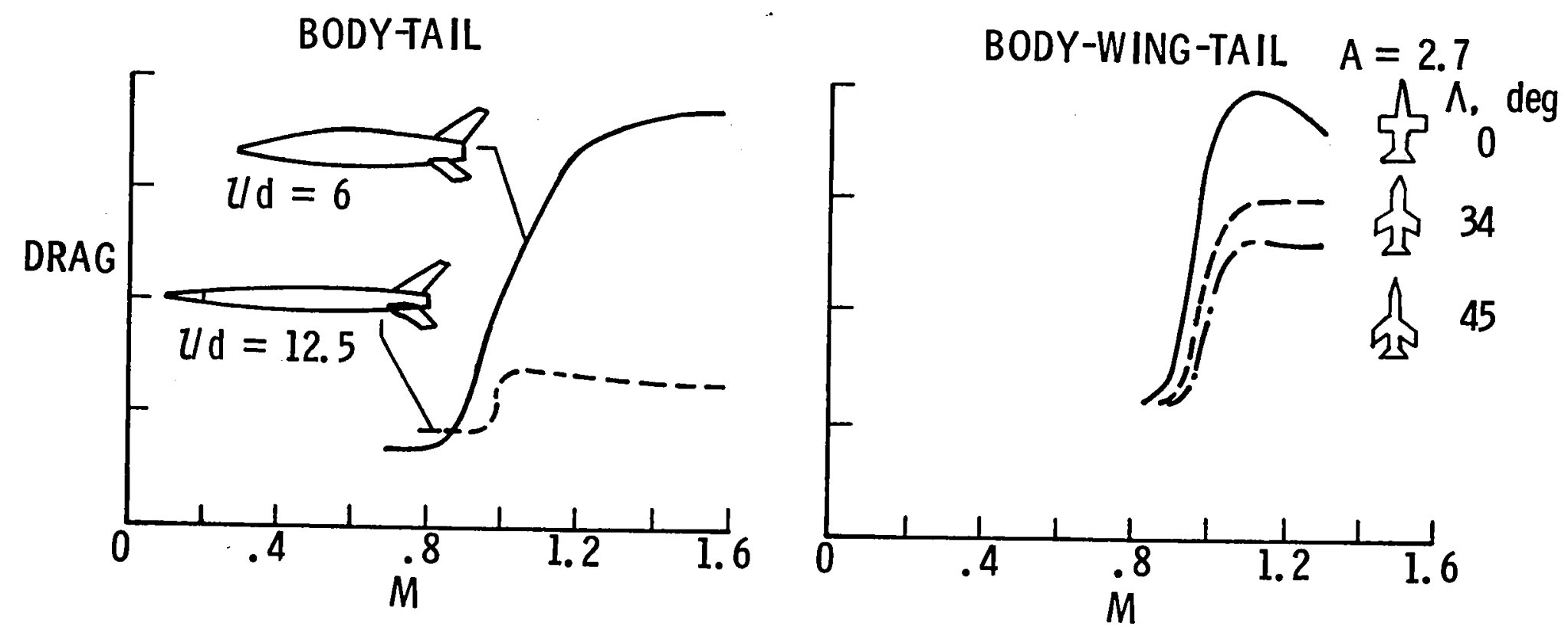

Figure 3.- Transonic drag characteristics from free-flight tests. 

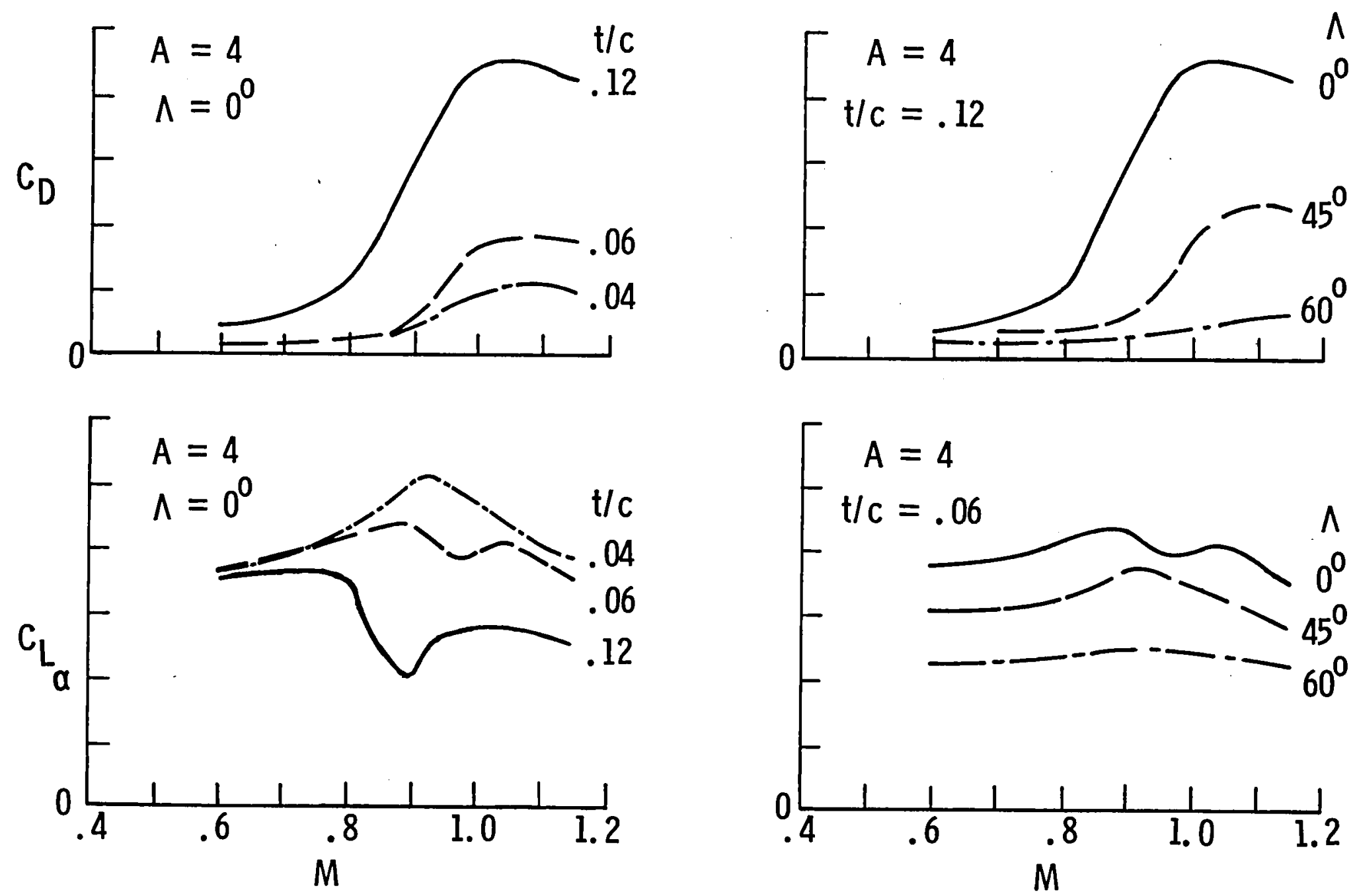

Figure 4.- Transonic lift and drag for various wings from transonic bump tests. 

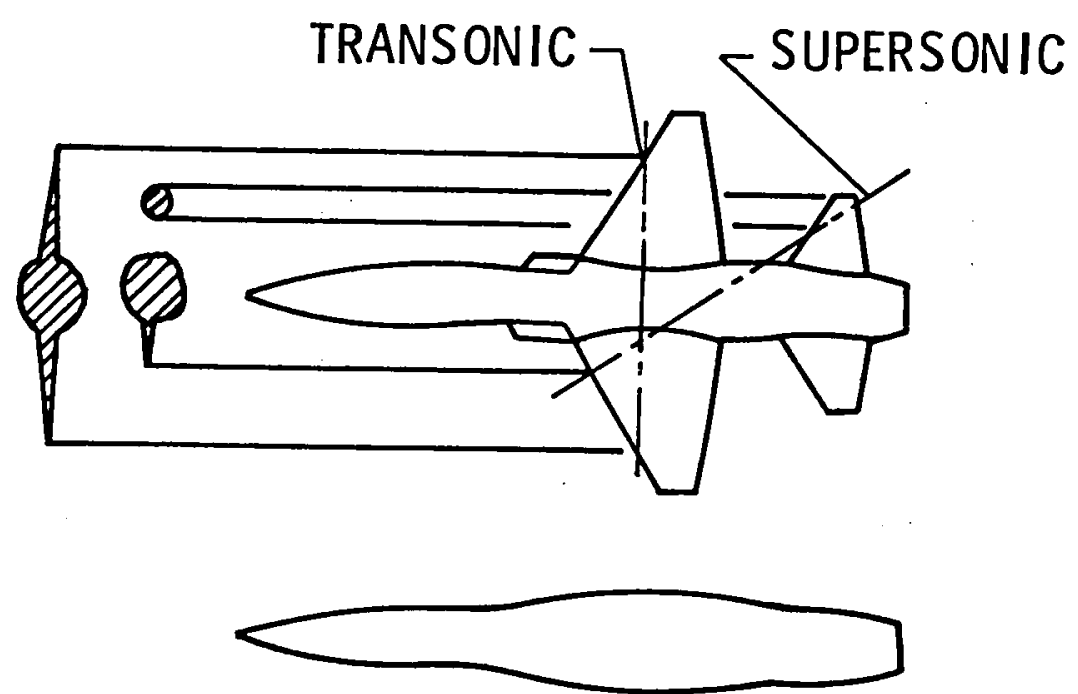

EQUIVALENT BODY

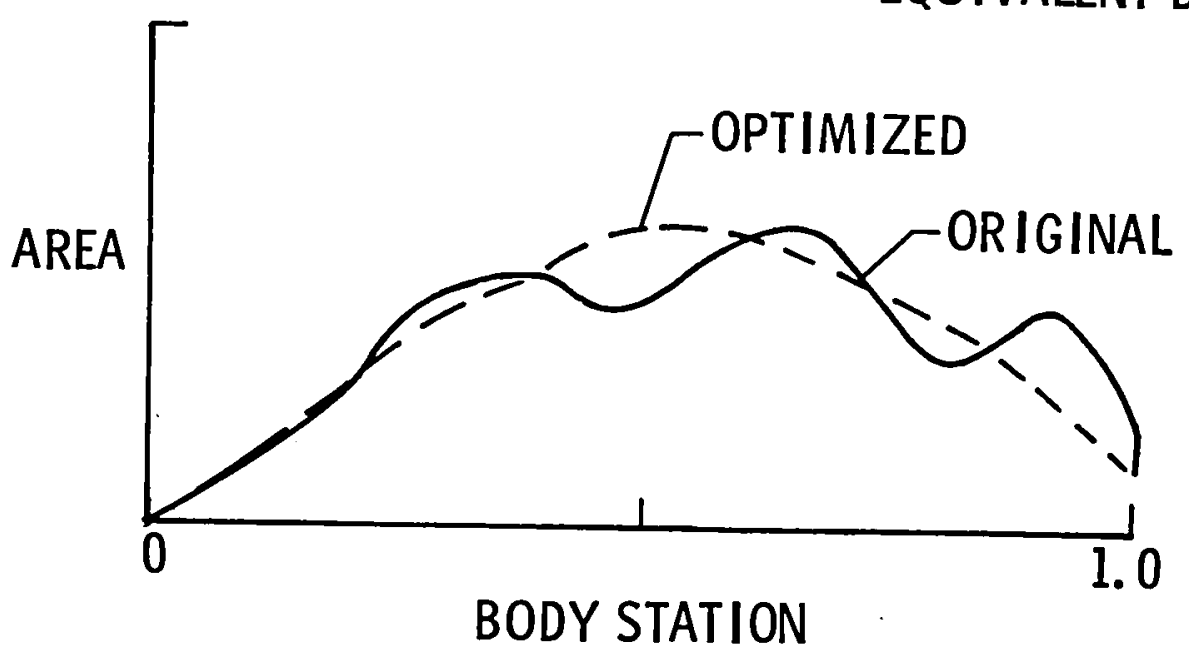

Figure 5.- Principle of area distribution. 


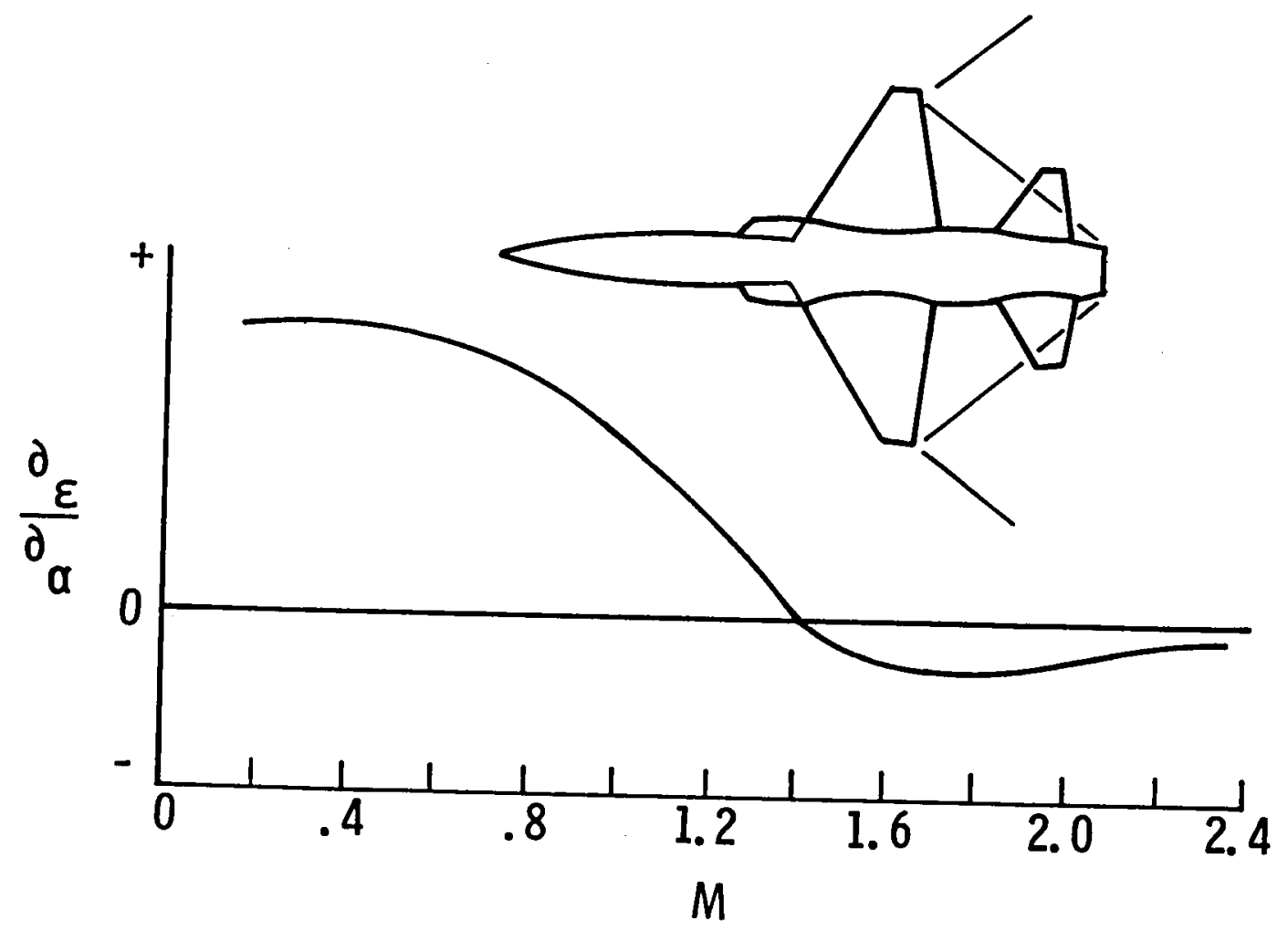

Figure 6.- Downwash characteristics as a function of Mach number. 


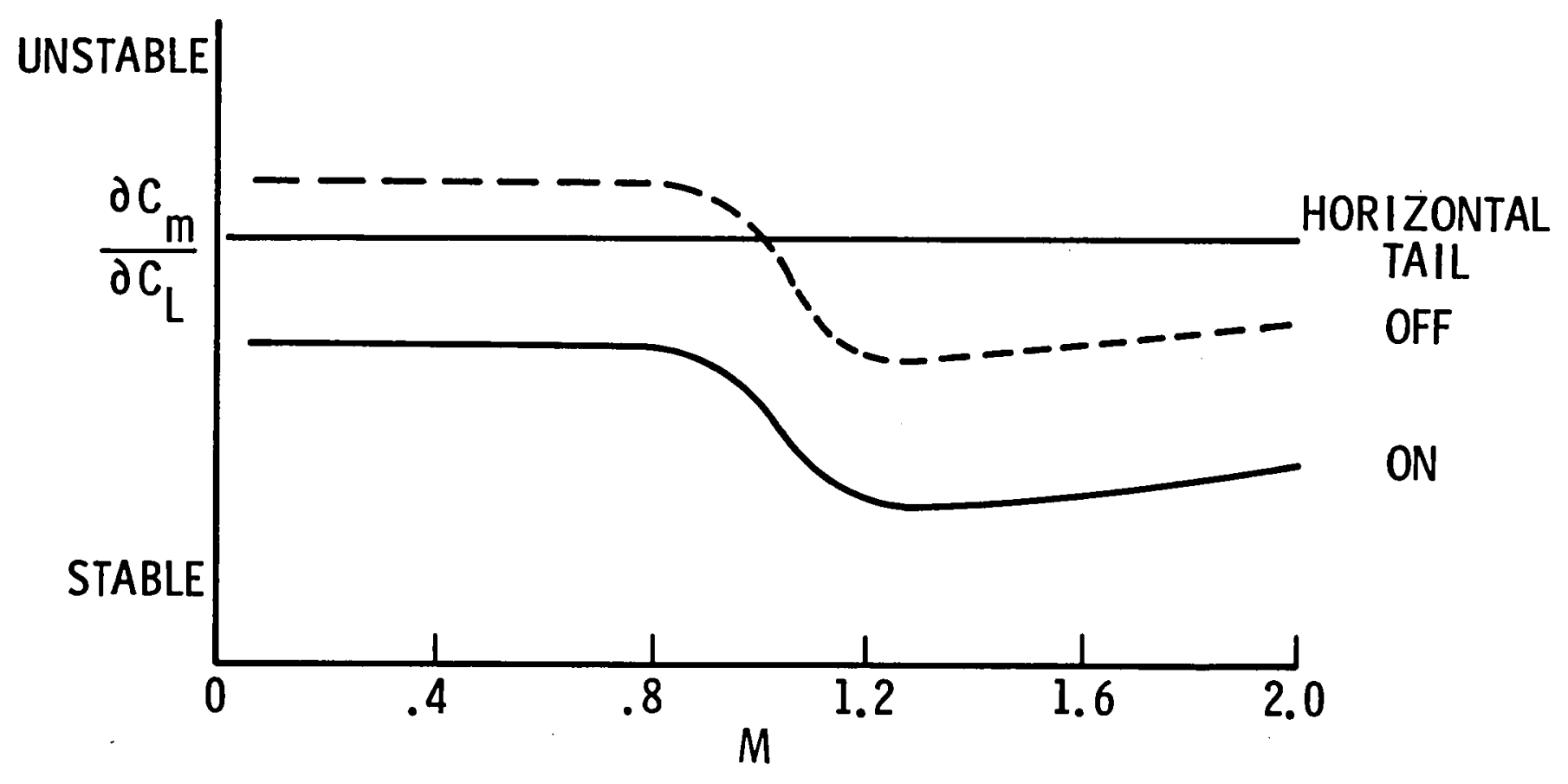

Figure 7.- Longitudinal stability characteristics as a function of Mach number. 

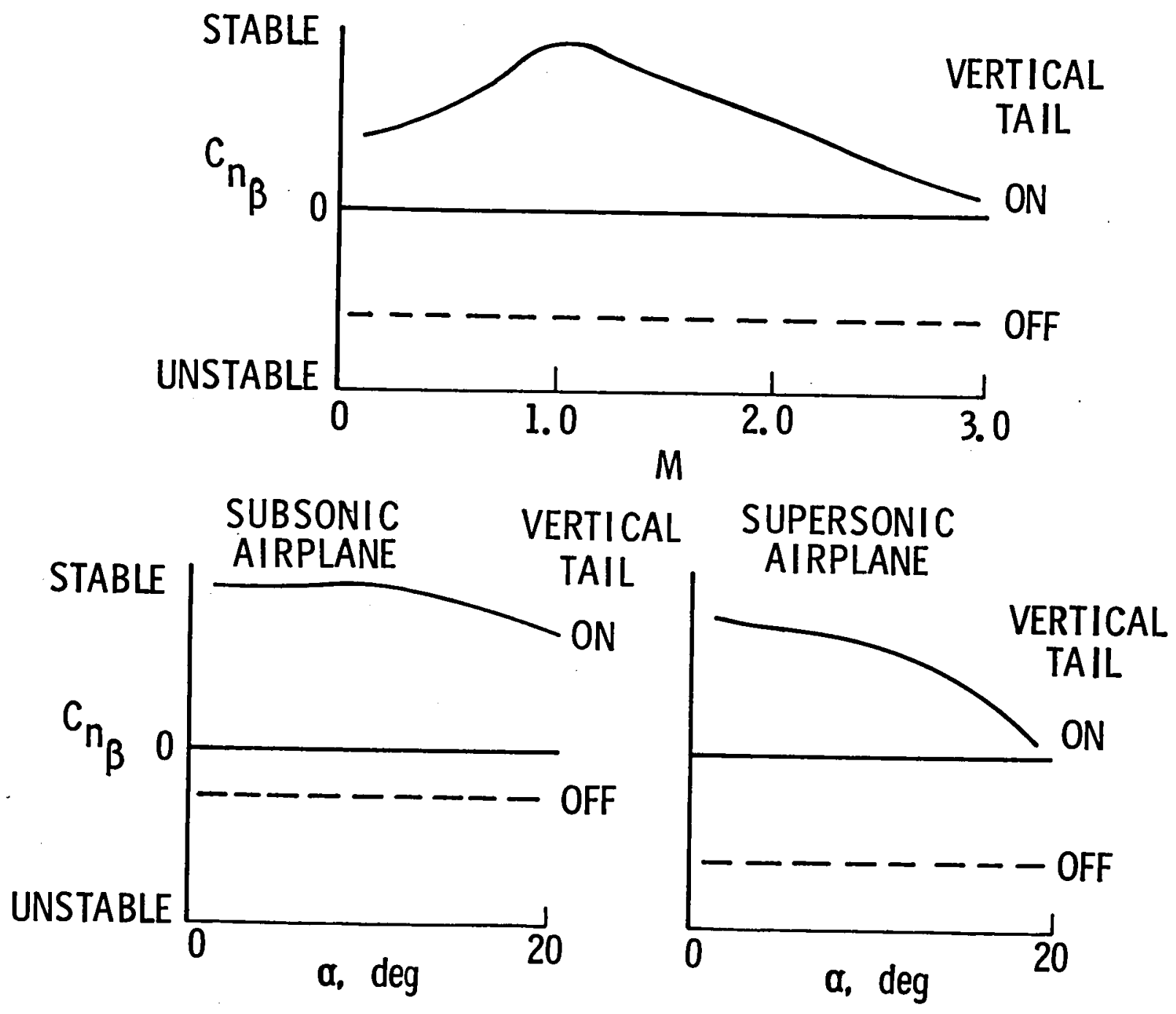

Figure 8.- Directional stability characteristics as a function of Mach number and angle of attack. 

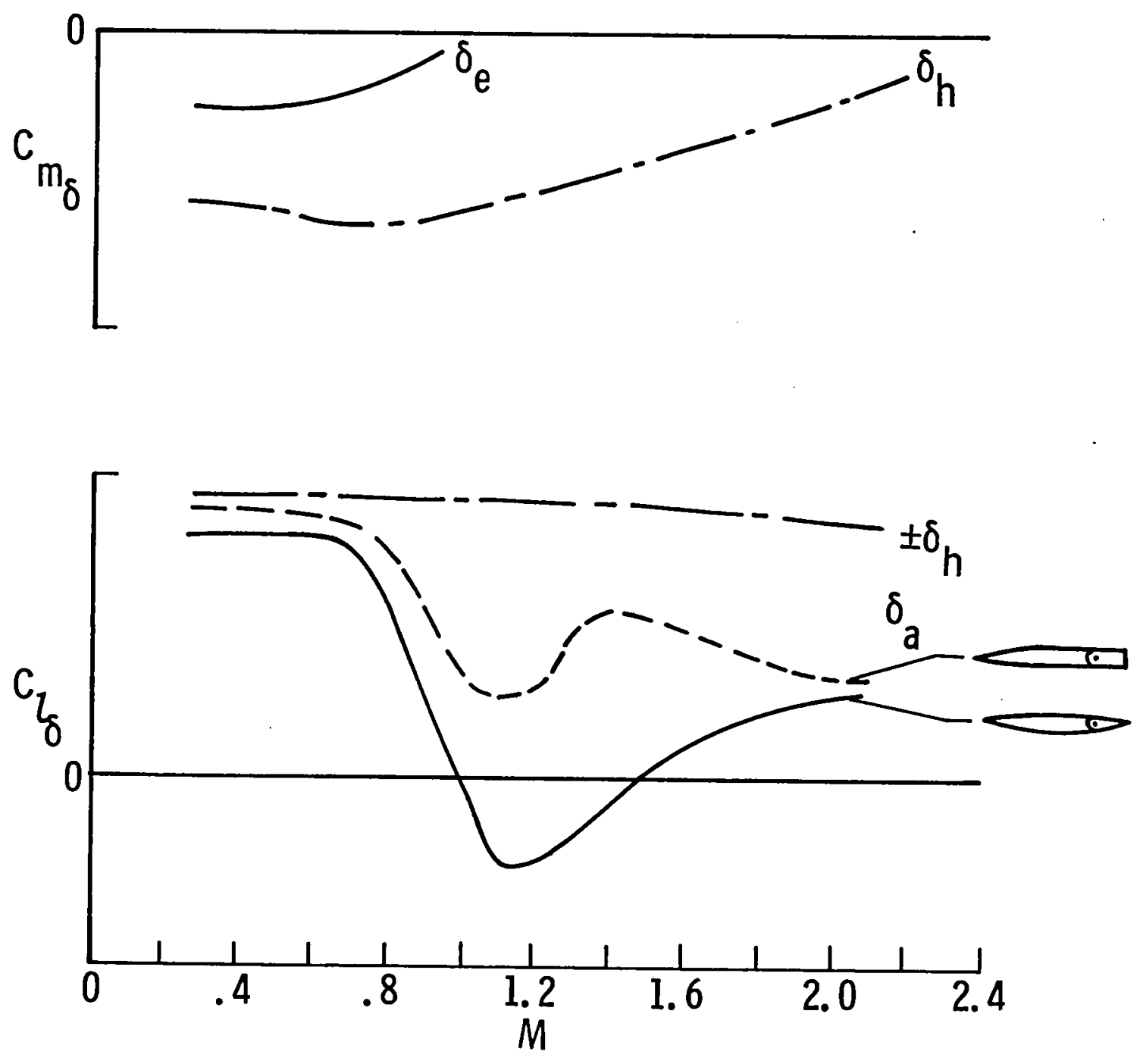

Figure 9.- Pitch and roll control effectiveness as a function of Mach number. 


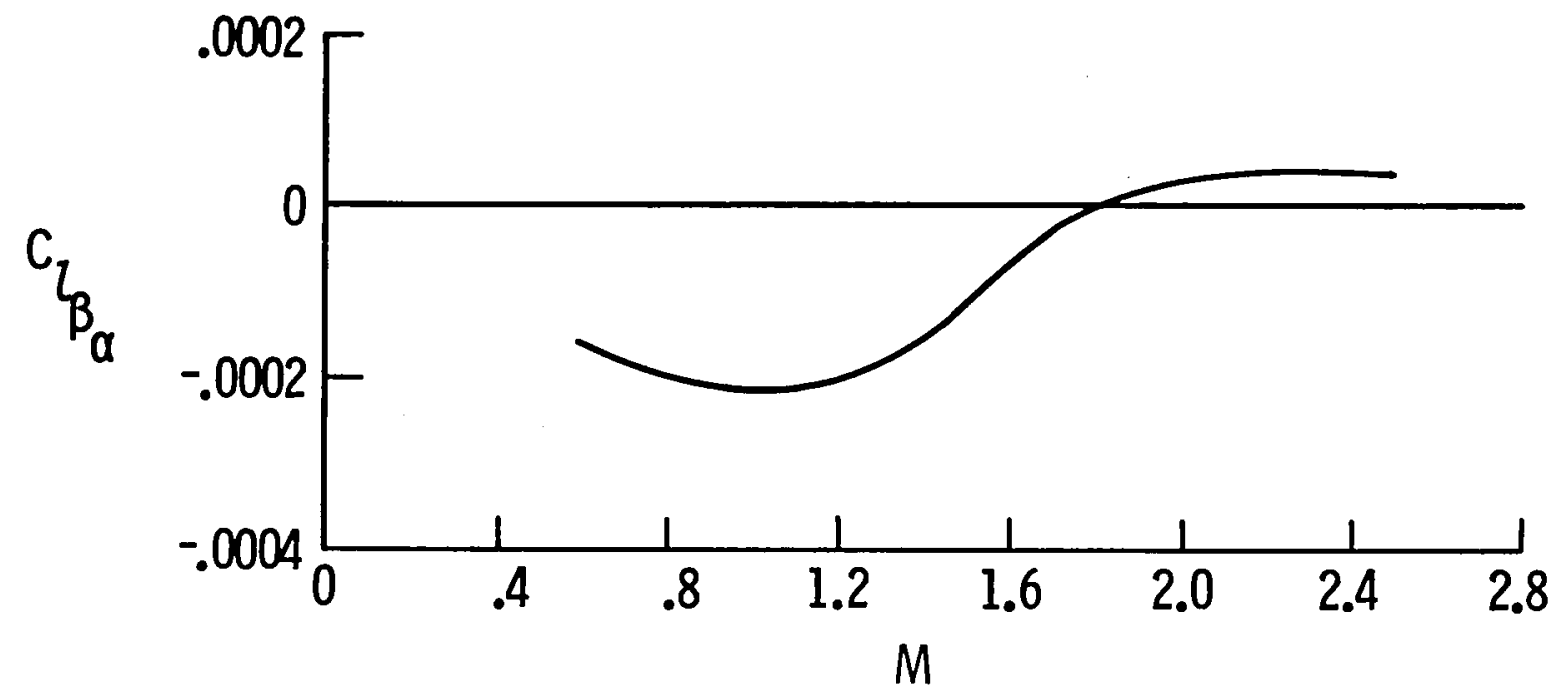

Figure 10.- Lateral characteristics as a function of Mach number, $57^{\circ}$ delta wing. 


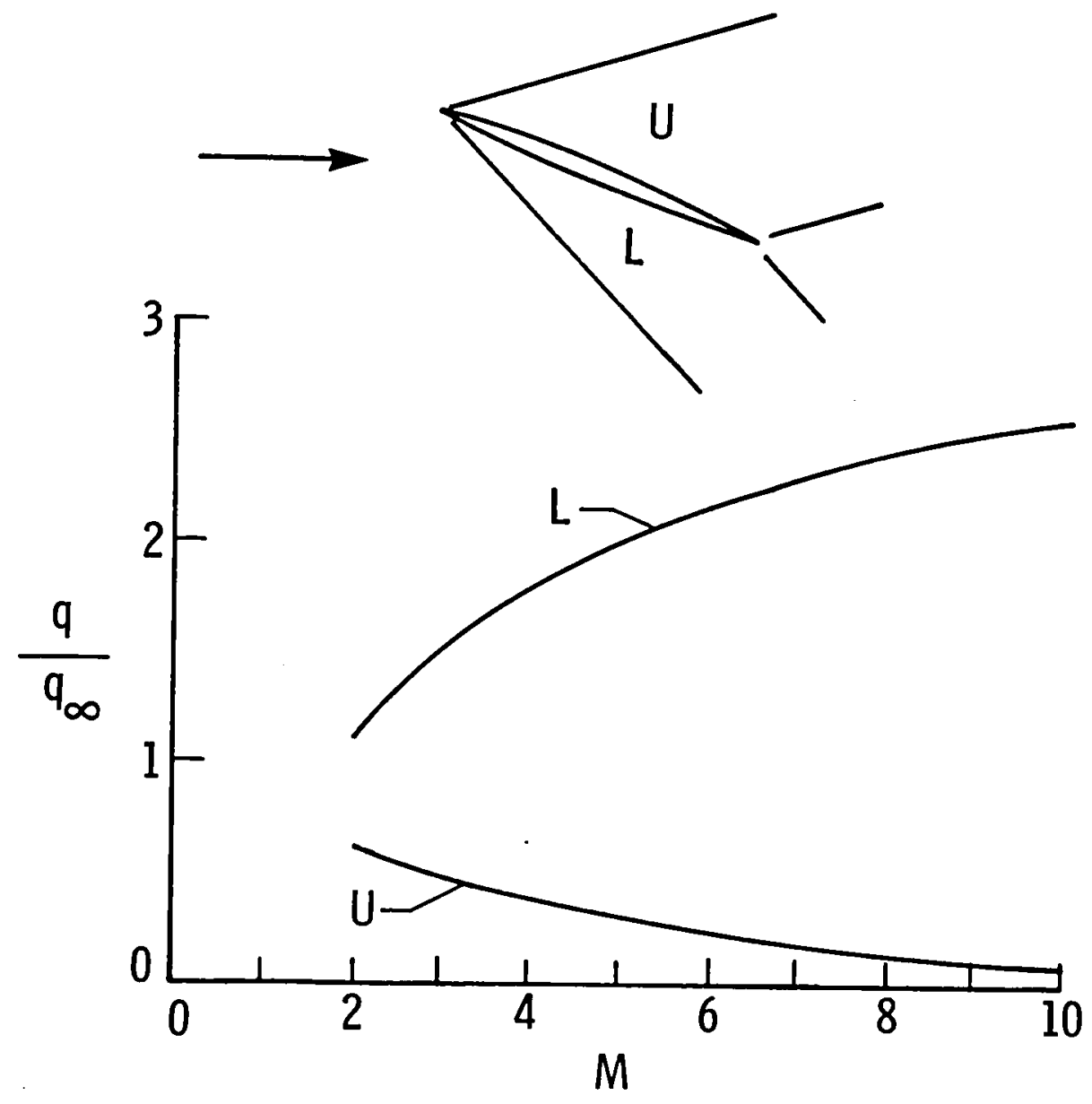

Figure 11.- Wing dynamic pressure fields at supersonic speeds, $\alpha=15^{\circ}$. 


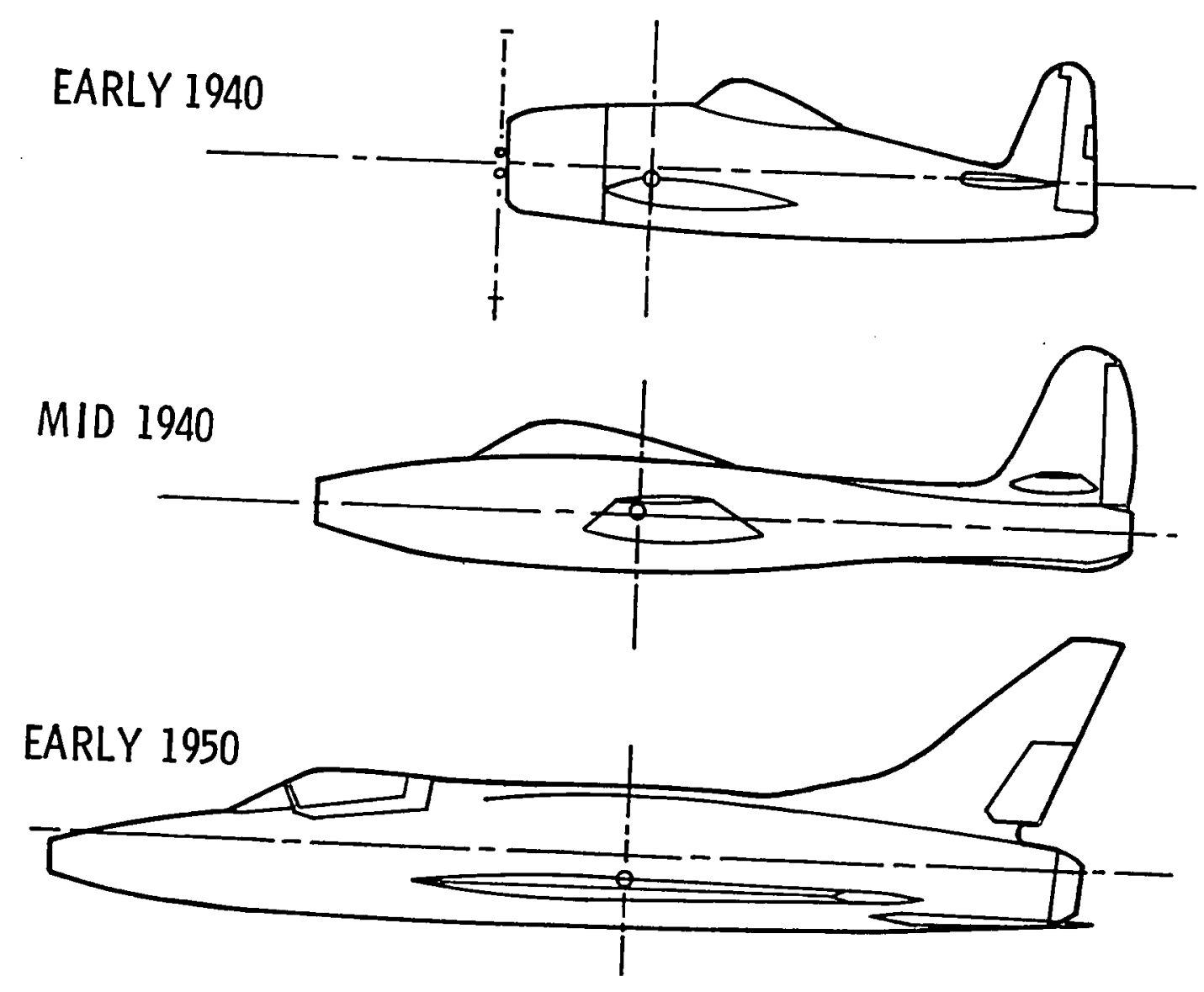

Figure 12.- Design trends of single-engine, single-place fighter airplanes. 


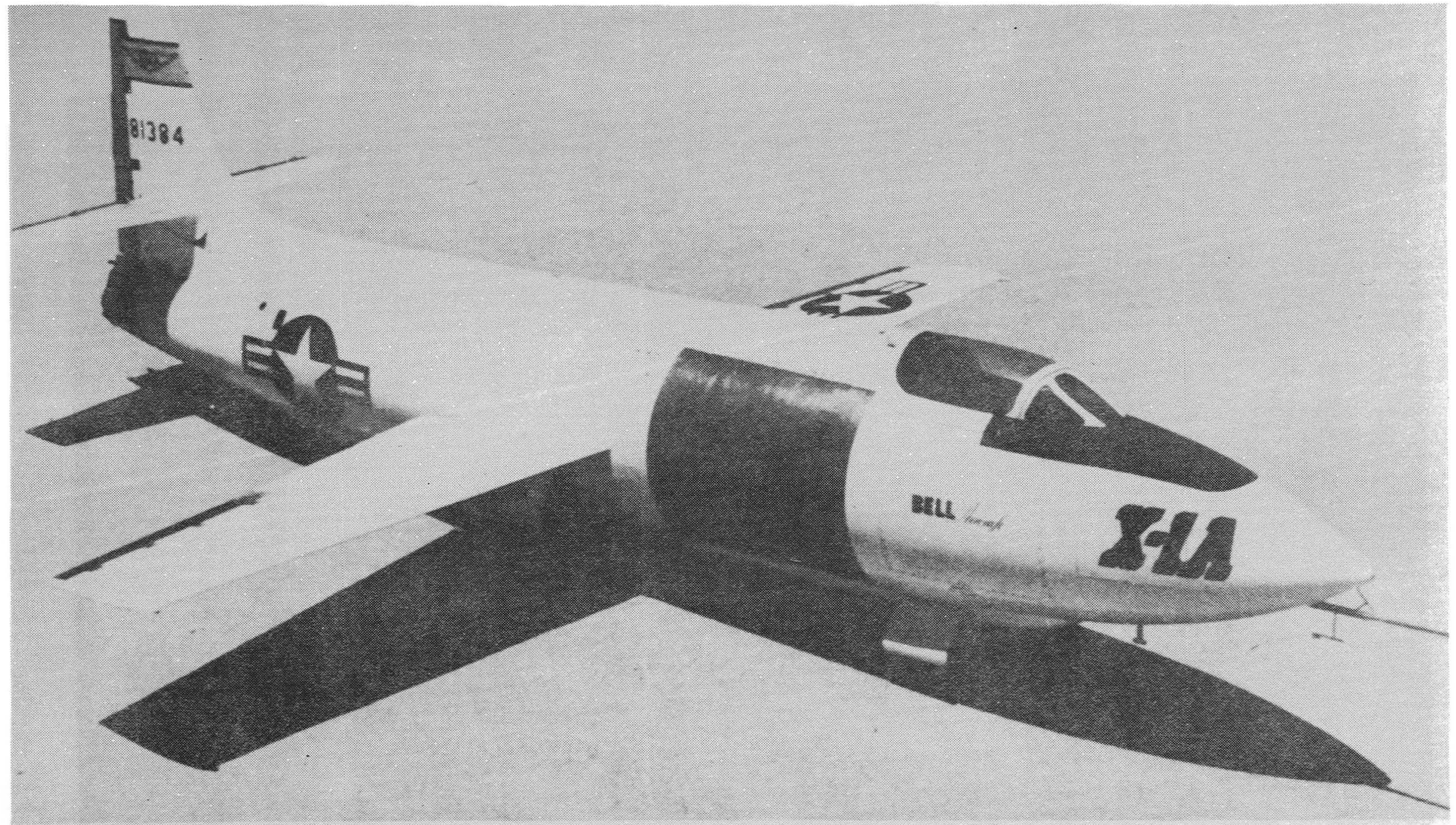

Figure 13. - The Bell X-1A research airplane. 


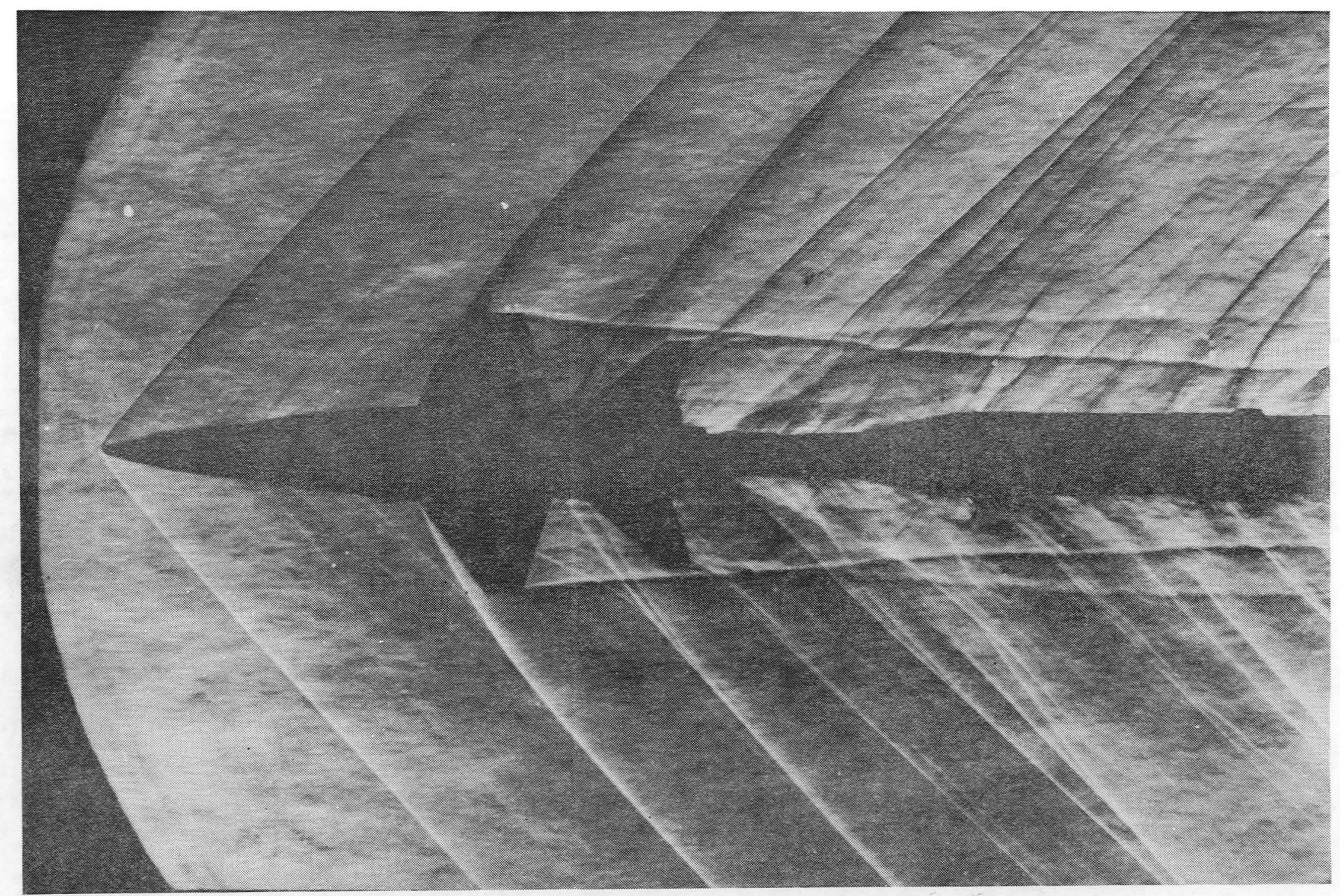

Figure 14.- Schlieren photograph of an $X-15$ mode1, $M=1.41$. 


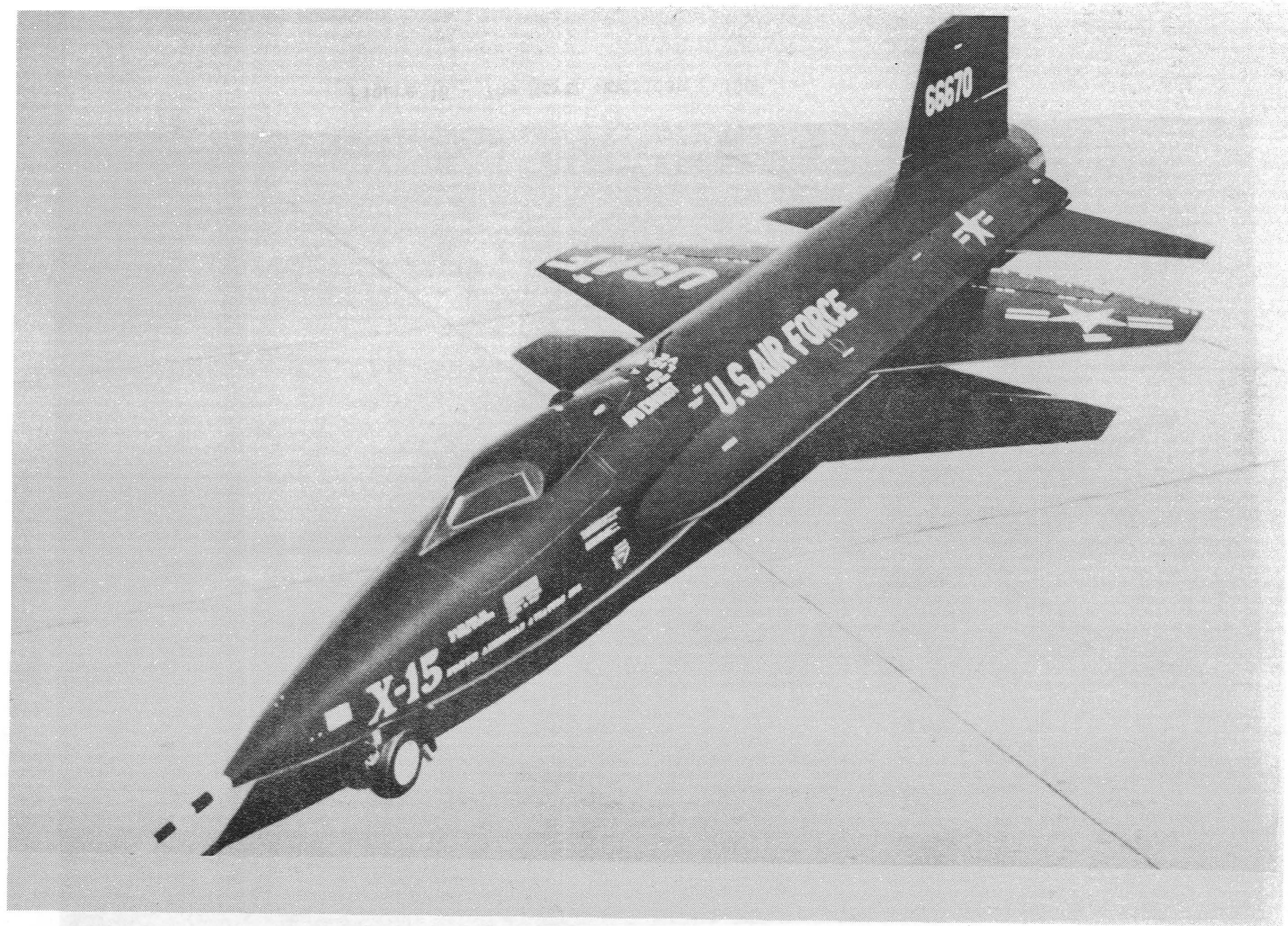

Figure 15.- The North American X-15 research airplane. 




Figure 16.- The North American F-100F. 


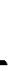




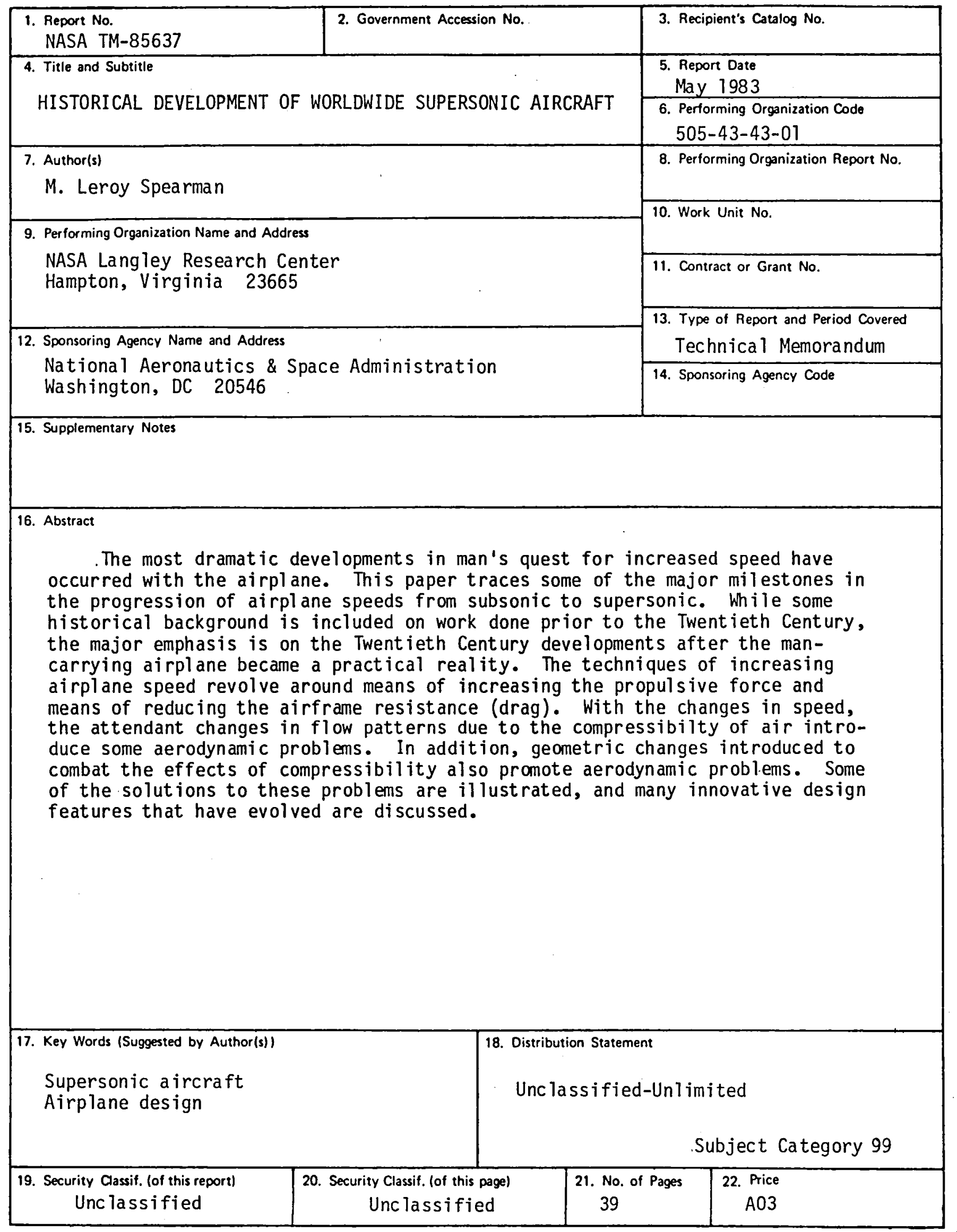


